\title{
Multiphysics Implementation of Electrokinetic Remediation Models for Natural Soils and Porewaters
}

López Vizcaíno, R. ${ }^{\text {a }}$, Yustres, A..$^{\text {,* }}$, León, M. J. ${ }^{\mathrm{b}}$, Saez, C. ${ }^{\mathrm{c}}$, Cañizares, P. ${ }^{\mathrm{c}}$, Rodrigo, M.A. ${ }^{\mathrm{c}}$, Navarro, V. ${ }^{\mathrm{b}}$

aDepartment of Chemical Engineering, Institute of Chemical \& Environmental Technologies, University of Castilla-La Mancha, Campus Universitario s/n, 13071 Ciudad Real, Spain

${ }^{\mathrm{b}}$ Geoenvironmental Group, Civil Engineering School, University of Castilla-La Mancha, Avda. Camilo José Cela s/n, 13071 Ciudad Real, Spain

'Department of Chemical Engineering, Faculty of Chemical Sciences\&Technologies, University of Castilla-La Mancha, Campus Universitario s/n, 13071 Ciudad Real, Spain

* Corresponding author: angel.yustres@ uclm.es, Civil Engineering School, University of Castilla-La Mancha, Avda. Camilo José Cela s/n, 13071 Ciudad Real, Spain 
GRAPHICAL ABSTRACT

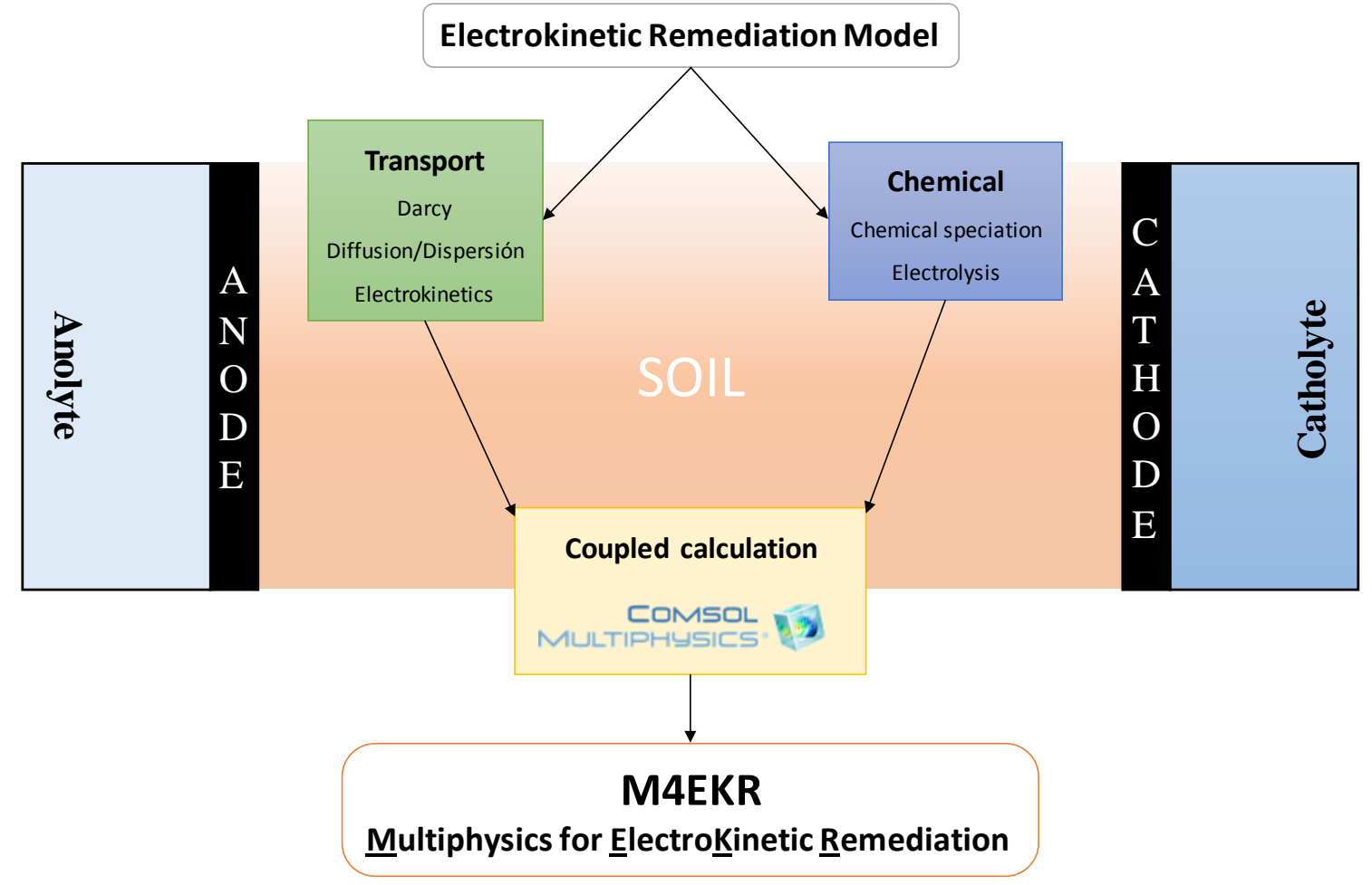




\begin{abstract}
Models of electrokinetic soil remediation systems have been developed significantly in recent decades. A wide range of physicochemical phenomena occurs in this type of process, which makes it difficult to capture all of the system's complexity in a model. Therefore, existing models do not attempt to simulate the behaviour of the entire geochemical system of natural soils and their porewaters but rather focus on the pollutant compounds of interest. This paper proposes a conceptual and numerical model that includes geochemical speciation other than the phenomena that have been described by other authors. In addition, a comparative modelling exercise is performed with a composition of natural porewater and a simplified equivalent composition. The results show that the buffering system of carbonates affects the temporal evolution and spatial distribution of the $\mathrm{pH}$. Because the $\mathrm{pH}$ controls many of the phenomena that occur during this type of remediation, simulations using realistic geochemical systems are critical.
\end{abstract}

\title{
KEYWORDS:
}

Electrokinetic soil remediation, Multiphysics simulation, geochemical modelling, unsaturated soil 


\section{INTRODUCTION}

Electrokinetic remediation (EKR) is a technology that has recently been applied in soil decontamination processes $[1,2]$. EKR technology allows contaminants of different ionic natures to be mobilised via various transport mechanisms that are generated by applying a low-intensity electric field between electrodes installed in the contaminated soil. This effect has generated significant interest in EKR technology in the field of in-situ soil decontamination. In addition, the energy requirements are generally low and can be supplied by renewable energy-based systems that are easily installed in any area to be decontaminated [3-5].

Electro-osmosis and electromigration are the main forms of mass transport that take place in the soil during an EKR process. The process of electro-osmosis causes the movement of water in the Debye layer, which is located along the surfaces of the soil particles. Generally, the soil surface charge is usually negative, so water that is capable of being mobilised through this mechanism has high concentrations of positive counter ions, and electro-osmotic transport is generally directed towards cathodes [6-8]. Through the process of electromigration, it is possible to mobilise various ionic species present in the porewater that are electrically attracted to the oppositely charged electrodes. Among these ionic species are protons and hydroxyl ions generated in the electrochemical reactions of water electrolysis:

$$
\begin{aligned}
& \mathrm{H}_{2} \mathrm{O} \leftrightarrow \frac{1}{2} \mathrm{O}_{2}+2 \mathrm{H}^{+}+2 \mathrm{e}^{-} \\
& 2 \mathrm{H}_{2} \mathrm{O}+2 \mathrm{e}^{-} \leftrightarrow \mathrm{H}_{2}+2 \mathrm{OH}^{-}
\end{aligned}
$$

which occur on the surfaces of the anodes (Eq. 1) and cathodes (Eq. 2). The movement of these species produces an acidic $\mathrm{pH}$ front towards the cathodic electrodes and a basic $\mathrm{pH}$ front towards the anodic electrodes, whose velocity, in addition to the 
electromigration process, is significantly influenced by advective/diffusive processes and the soil's buffering capacity [9-11]. The $\mathrm{pH}$ fronts form a pronounced $\mathrm{pH}$ gradient in the soil that can favour the precipitation/solubilisation of species, adsorption processes, and ionic exchange between the soil and the porewater and, importantly, influence the chemical speciation of substances in the medium.

The coupling of these phenomena makes the design, analysis, and implementation of an EKR process in contaminated soil a very complex task. The development of mathematical models is necessary to characterise the interactions of the many physical, chemical, and electrochemical processes that occur simultaneously and therefore facilitate making predictions about the scaling of the technology. For this reason, the development of mathematical models of EKR processes has been important over the last 25 years. Shapiro et al. [7] and Shapiro and Probstein [8] developed a one-dimensional mathematical model that considered the chemical equilibria of substances in the porewater, electrochemical reactions, diffusive and electro-osmotic transport, and ionic electromigration. The model was developed for the decontamination of a synthetic soil (kaolin) spiked with acetic acid and phenol. This model was improved by adding coupling complexation, adsorption and precipitation/dissolution processes by Jacobs et al. [12] and extended to a twodimensional domain by Jacobs and Probstein [13]. Other authors [14-16] developed a one-dimensional theoretical model that was applied to remove lead spiked in a mixture of kaolinite and sand, for which they estimated the $\mathrm{pH}$ profiles generated in the soil. Mascia et al. [17] proposed a similar model for the removal of cadmium. These models were generalised by Paz-Garcia et al. [9] for application to soils contaminated with many metals. Other authors $[18,19]$ have developed two-dimensional models that focused on the electrokinetic removal of metals and its application, in particular, to the remediation of soils contaminated with copper. Ribeiro et. al. [20] developed a model adapted for the 
removal of organic pollutants and used atrazine as an example. A three-dimensional model has also been developed and used to simulate the electrokinetic transport of ions in soils under unsaturated conditions assuming that the lines of the electrical current in a soil during the application of an electrical gradient are analogous to the lines of a water current generated under a hydraulic gradient $[21,22]$.

In this context, as proposed by Al-Hamdan \& Reddy [23], many previous models utilise simplified geochemical systems because they generally contain fewer than 10 species, taking into account the reactants and products of the chemical and electrochemical reactions that can occur. This implies that the chemical speciation generated in the EKR process is quite limited and cannot faithfully reproduce the behaviour observed in real applications, where the composition of the natural porewater can be very complex. As mentioned above, chemical speciation is strongly related to the $\mathrm{pH}$ of the medium, which determines the extent to which many physico-chemical processes that directly affect the efficacy of an EKR process can be developed.

This study developed a model, M4EKR (Multiphysiscs for ElectroKinetic Remediation), that is applicable to electrokinetic remediation processes in natural unsaturated soils for the removal of ionic species present in porewater. An extended geochemical system with 34 species that are involved in 24 chemical equilibria resulting from the presence of the most common major ions in many natural groundwaters was studied. The model includes the transport of species due to electro-osmosis, electromigration, diffusion and advective flow.

After describing the proposed formulation, the scope of the model is illustrated by simulating an EKR process of a natural soil and porewater as opposed to the synthetic saturating waters that have been proposed in other studies. The results show the descriptive capacity of the proposed model. Finally, the same process is analysed 
assuming a reduced geochemical model. This exercise illustrates the limitations of simplified models that do not allow several relevant processes that occur in natural porewaters to be simulated. The results confirm the convenience of using extended geochemical models to improve the characterisation and design of EKR processes in soils under natural conditions.

\section{CONCEPTUAL AND NUMERICAL MODEL}

The proposed model is a model of the reactive transport of solutes in partially saturated soils subjected to an external electrical gradient. For conceptual simplification, isothermal conditions (298.15 K over the entire domain) are assumed, and the gas pressure (GP) remains constant and equal to atmospheric pressure

\subsection{Water transport}

The balance of the mass of water per unit volume in a porous medium is given by the expression:

$$
\frac{\partial m_{\mathrm{w}}}{\partial t}+\nabla \cdot \mathbf{1}_{\mathrm{w}}=0
$$

where $\nabla \cdot$ is the divergence operator, $\mathbf{l}_{\mathrm{w}}$ is the mass flow of water $\left(\mathrm{kg} \mathrm{m}^{-2} \mathrm{~s}^{-1}\right)$, and $m_{\mathrm{w}}$ is the mass of water per unit total volume $\left(\mathrm{kg} \mathrm{m}^{-3}\right)$, which is defined as:

$m_{\mathrm{w}}=\phi \cdot S r \cdot \rho_{\mathrm{w}}$

where $\phi$ is the porosity, $\rho_{\mathrm{w}}$ is the water density, and $S r$ is the degree of saturation of the soil. $S r$ is modelled using van Genuchten's retention curve [24], which is defined via the expression:

$$
S r=\left(1+\left(\alpha_{\mathrm{VG}} \cdot s\right)^{n_{\mathrm{VG}}}\right)^{-m_{\mathrm{VG}}}
$$


where $\alpha_{\mathrm{VG}}, n_{\mathrm{VG}}$ and $m_{\mathrm{VG}}$ are fitting parameters, and $s$ is the matric suction, which is given by the difference between the gas pressure and liquid pressure, $P_{\mathrm{G}}-P_{\mathrm{L}}$.

The mass flow of water is defined by the sum of the hydraulic flux contributions $\left(\mathbf{l}_{\mathrm{w}}^{\mathrm{h}}\right)$, which are estimated via Darcy's law, and the electro-osmotic flux $\left(\mathrm{l}_{\mathrm{w}}^{\mathrm{e} 0}\right)$, which is defined by the semi-empirical Helmholtz-Smoluchowski formulation [25]. Therefore, in the proposed model, we have:

$$
\begin{aligned}
& \mathbf{l}_{\mathrm{w}}=\mathbf{l}_{\mathrm{w}}^{\mathrm{h}}+\mathbf{l}_{\mathrm{w}}^{\mathrm{eo}}=\rho_{\mathrm{w}} \cdot\left(\mathbf{q}_{\mathrm{w}}^{\mathrm{h}}+\mathbf{q}_{\mathrm{w}}^{\mathrm{eo}}\right)=\rho_{\mathrm{w}} \cdot \mathbf{q}_{\mathrm{w}} \\
& \mathbf{q}_{\mathrm{w}}^{\mathrm{h}}=-K_{\mathrm{e}}^{\mathrm{h}} \cdot\left(\nabla P_{\mathrm{L}}+g \cdot \rho_{\mathrm{w}} \cdot \nabla z\right) \\
& K_{\mathrm{e}}^{\mathrm{h}}=K_{\mathrm{sat}}^{\mathrm{h}} \cdot k_{r e l}^{h}=K_{\mathrm{sat}}^{\mathrm{h}} \cdot S r^{3} \\
& \mathbf{q}_{\mathrm{w}}^{\mathrm{eo}}=-K_{\mathrm{e}}^{\mathrm{eo}} \cdot \nabla E=-K_{\mathrm{sat}}^{\mathrm{eo}} \cdot S r^{3} \cdot \nabla E
\end{aligned}
$$

where $K_{\mathrm{e}}^{\mathrm{h}}$ is the effective hydraulic permeability of the soil, which is calculated by multiplying the saturated permeability $\left(K_{\text {sat }}^{\mathrm{h}}\right.$ ) by a relative permeability function. A Brooks and Corey-type power function was chosen for the relative permeability [26] with an exponent of 3. In addition, $\nabla$ is the gradient differential operator, $g$ is gravity, $z$ is the vertical coordinate, $E$ is the electric potential, $K_{\mathrm{e}}^{\mathrm{eo}}$ is the effective electro-osmotic permeability of the soil, which is calculated using the same formulation employed in the calculation of $K_{\mathrm{e}}^{\mathrm{h}}$, and $K_{\text {sat }}^{\mathrm{eo}}$ is the saturated electro-osmotic permeability.

\subsection{Chemical species transport}

The proposed geochemical system includes a total of $N$ species generated from the combination of $M$ components selected among the species [27]. $M-2$ equilibrium equations of the total mass of each component are defined (one for each except for $\mathrm{Cl}^{-}$, 
which is obtained by electroneutrality, and for $\mathrm{H}_{2} \mathrm{O}$, which was proposed in Eq. 3), generically formulated as:

$\frac{\partial m_{\mathrm{m}}}{\partial t}+\nabla \cdot \mathbf{l}_{\mathrm{m}}=R_{\mathrm{m}}$

where $m_{\mathrm{m}}$ is the total mass of component $m$ per unit total volume $\left(\mathrm{mol} \mathrm{m}^{-3}\right), \mathbf{l}_{\mathrm{m}}$ is the total molar flux of component $m\left(\mathrm{~mol} \mathrm{~m} \mathrm{~m}^{-2} \mathrm{~s}^{-1}\right)$, and $R_{\mathrm{m}}$ is the rate of production or consumption of component $m\left(\mathrm{~mol} \mathrm{~m}^{-3} \mathrm{~s}^{-1}\right)$. The parameter $m_{\mathrm{m}}$ is defined as:

$m_{\mathrm{m}}=\phi \cdot S r \cdot \rho_{\mathrm{w}} \cdot C_{\mathrm{m}}$

where $C_{\mathrm{m}}$ is the total molal concentration of component $m\left(\mathrm{~mol} \mathrm{~kg}_{\mathrm{w}}{ }^{-1}\right)$.

Several transport mechanisms of species through the soil occur in EKR processes, so $\mathbf{l}_{\mathrm{m}}$ will be the sum of each of the contributions associated with the involved mechanisms, including advective flow generated by the hydraulic gradient $\left(\mathbf{l}_{\mathrm{m}}^{\mathrm{h}}\right)$ and the electrical gradient $\left(\mathbf{l}_{\mathrm{m}}^{\mathrm{eo}}\right)$, electromigratory flow $\left(\mathbf{l}_{\mathrm{m}}^{\mathrm{em}}\right)$ and diffusive-dispersive flow $\left(\mathbf{l}_{\mathrm{m}}^{\mathrm{dif}}\right)$ :

$\mathbf{l}_{\mathrm{m}}=\mathbf{l}_{\mathrm{m}}^{\mathrm{h}}+\mathbf{l}_{\mathrm{m}}^{\mathrm{eo}}+\mathbf{l}_{\mathrm{m}}^{\mathrm{em}}+\mathbf{l}_{\mathrm{m}}^{\mathrm{dif}}$

where each of these mass flows is defined as:

$$
\begin{aligned}
& \mathbf{l}_{\mathrm{m}}^{\mathrm{h}}=\mathbf{l}_{\mathrm{w}}^{\mathrm{h}} \cdot C_{\mathrm{m}} \\
& \mathbf{l}_{\mathrm{m}}^{\mathrm{eo}}=\mathbf{l}_{\mathrm{w}}^{\mathrm{eo}} \cdot C_{\mathrm{m}} \\
& \mathbf{l}_{\mathrm{m}}^{\mathrm{em}}=\rho_{\mathrm{w}} \cdot \sum_{i=1}^{N} \alpha_{\mathrm{i}}^{\mathrm{m}} \cdot c_{\mathrm{i}} \cdot \mathbf{q}_{\mathrm{i}}^{\mathrm{em}} \\
& \mathbf{l}_{\mathrm{m}}^{\mathrm{dif}}=-\rho_{\mathrm{w}} \cdot \sum_{i=1}^{N} D_{\mathrm{i}} \cdot \alpha_{\mathrm{i}}^{\mathrm{m}} \cdot \nabla c_{\mathrm{i}}
\end{aligned}
$$


where $\alpha_{\mathrm{i}}^{\mathrm{m}}$ is the molar contribution to the total concentration of component $m$ of species $i$ (see Section 2.5), and $c_{\mathrm{i}}$ is the molal concentration of the species. In addition, $\mathbf{q}_{\mathrm{i}}^{\mathrm{em}}$ is the migration velocity, which is defined via the expression:

$\mathbf{q}_{\mathrm{i}}^{\mathrm{em}}=-\mu_{\mathrm{i}}^{\mathrm{e}} \cdot \nabla E$

where $\mu_{\mathrm{i}}^{\mathrm{e}}$ is the effective ionic mobility characteristic of species $i$ and is defined via the expression proposed by Mattson et al.[21]:

$\mu_{\mathrm{i}}^{\mathrm{e}}=\phi \cdot S r \cdot \tau \cdot \gamma_{\mathrm{i}} \cdot \mu_{\mathrm{i}}^{\mathrm{o}}$

where, $\gamma_{i}$ is the coefficient of activity of species $i$ (see Section 2.5), $\mu_{\mathrm{i}}^{0}$ is its ionic mobility at infinite dilution in water $\left(\mathrm{m}^{2} \mathrm{~V}^{-1} \mathrm{~s}^{-1}\right)$, and $\tau$ is the tortuosity of the medium. Some authors have proposed different empirical models [28] that link the volumetric soil water content $(\phi \cdot S r)$ and the tortuosity factor using, among others, power functions. These formulations can resemble the power function dependence on the degree of saturation that it is used in the expression of the relative permeability (Eqs. 8 and 9). However, these empirical models are neither valid for all kind of soils nor for all ionic species. Consequently, for the sake of simplicity, a unique and constant value of tortuosity is considered in the present work since the main objective of the model is to understand the fundamental physical-chemical phenomena during an EKR process.

The effective diffusion coefficient of each species, $D_{\mathrm{i}}^{\mathrm{e}}$, is estimated via the expression:

$D_{\mathrm{i}}^{\mathrm{e}}=\phi \cdot S r \cdot \tau \cdot D_{\mathrm{i}}^{\mathrm{o}}$

where $D_{i}^{0}$ is the binary diffusion coefficient in water $\left(\mathrm{m}^{2} \mathrm{~s}^{-1}\right)$. The effective diffusion/dispersion coefficient $D_{\mathrm{i}}$ for one-dimensional flow is estimated via [29]: 
$D_{\mathrm{i}}=D_{\mathrm{i}}^{\mathrm{e}}+\delta_{\mathrm{i}}^{\mathrm{L}} \cdot\left|\mathbf{q}_{\mathrm{i}}^{\mathrm{em}}+\mathbf{q}_{\mathrm{w}}^{\mathrm{h}}+\mathbf{q}_{\mathrm{w}}^{\mathrm{eo}}\right|$

where $\delta_{\mathrm{i}}^{\mathrm{L}}$ is the longitudinal dispersivity coefficient (m).

Because it is easier to find values of the binary diffusion coefficient than values of the ionic mobility at infinite dilution in the literature, $\mu_{\mathrm{i}}^{0}$ is estimated by means of $D_{\mathrm{i}}^{\mathrm{o}}$ via the Nernst-Einstein equation [30]:

$\mu_{\mathrm{i}}^{\mathrm{o}}=\frac{D_{\mathrm{i}}^{\mathrm{o}} \cdot z_{\mathrm{i}} \cdot F}{R \cdot T}$

where $z_{\mathrm{i}}$ is the charge number of species $i, F\left(\mathrm{C} \mathrm{mol}^{-1}\right)$ and $R\left(\mathrm{~J} \mathrm{~mol}^{-1} \mathrm{~K}^{-1}\right)$ are the Faraday and ideal gas constants, respectively, and $T$ is the temperature $(\mathrm{K})$, which, as discussed previously, is assumed to be constant.

The generation or consumption of the total mass of any component in the soil does not occur in any case, so $\mathrm{R}_{\mathrm{m}}$ is zero in the $M-2$ balance equations. The only electrochemical reactions are the electrolysis of water, and they take place in electrolyte wells.

\subsection{Transport of electric charge}

The distribution of the electrical potential in the system must satisfy the equilibrium equation of the total electric charge:

$$
\frac{\partial Q}{\partial t}+\nabla \cdot \mathbf{i}=R_{\mathrm{Q}}
$$

where $Q$ is the total electric charge $\left(\mathrm{C} \mathrm{m}^{-3}\right), R_{\mathrm{Q}}$ is the rate of generation/consumption of the electric charge $\left(\mathrm{C} \mathrm{m}^{-3} \mathrm{~s}^{-1}\right)$, and $\mathbf{i}$ is the total current density $\left(\mathrm{A} \mathrm{m}^{-2}\right)$, which is calculated by applying Ohm's law, formulated generically as:

$\mathbf{i}=-\sigma_{\mathrm{a}} \cdot \nabla E$ 
where $\sigma_{\mathrm{a}}$ is the apparent electrical conductivity obtained via the formulation defined by Rhoades [31]. In it, the soil is assumed to be a system in which electrical current can follow three different conducting paths: (1) exclusively through the liquid phase, (2) exclusively through the surface of the solid phase, and (3) through a combination of these elements. The conductivity of the solid phase, $\sigma_{\mathrm{s}}$, is estimated by the empirical relationship presented by Rhoades in Friedman [32]:

$$
\sigma_{\mathrm{s}}=0.023 \cdot \%_{\text {clay }}-0.0209
$$

where $\sigma_{\mathrm{s}}$ is defined in $\mathrm{dS} \mathrm{m} \mathrm{m}^{-1}$, and $\%$ clay is the weight percentage of the clay soil particles considered. In addition, the conductivity of the aqueous phase in the pores, $\sigma_{\mathrm{w}}$, is assumed to be constant and is estimated via [33]:

$$
\begin{aligned}
& \sigma_{\mathrm{w}}=\sum_{\mathrm{i}=1}^{\mathrm{N}}\left(\lambda_{\mathrm{o}, \mathrm{i}} \cdot \gamma_{\mathrm{i}} \cdot c_{\mathrm{i}}\right) \\
& \lambda_{\mathrm{o}, \mathrm{i}}=\frac{\rho_{w} \cdot D_{\mathrm{i}}^{\mathrm{o}} \cdot z_{\mathrm{i}}^{2} \cdot F^{2}}{R \cdot T}
\end{aligned}
$$

where $\lambda_{\mathrm{o}, \mathrm{i}}$ is the ionic molal conductivity of species $i$. Given the condition of electroneutrality throughout the system and assuming that no charge accumulation capacity is present during the EKR process, it is assumed that $\partial Q / \partial t=0$ at all times [13]. Therefore, the electric charge equilibrium is reduced to solving the expression:

$$
\nabla \cdot \mathbf{i}=0
$$

\subsection{Mass balance in electrolyte wells.}

Figure 1 shows a conceptual model of the configuration of the electrodes and electrolyte wells in the model. 


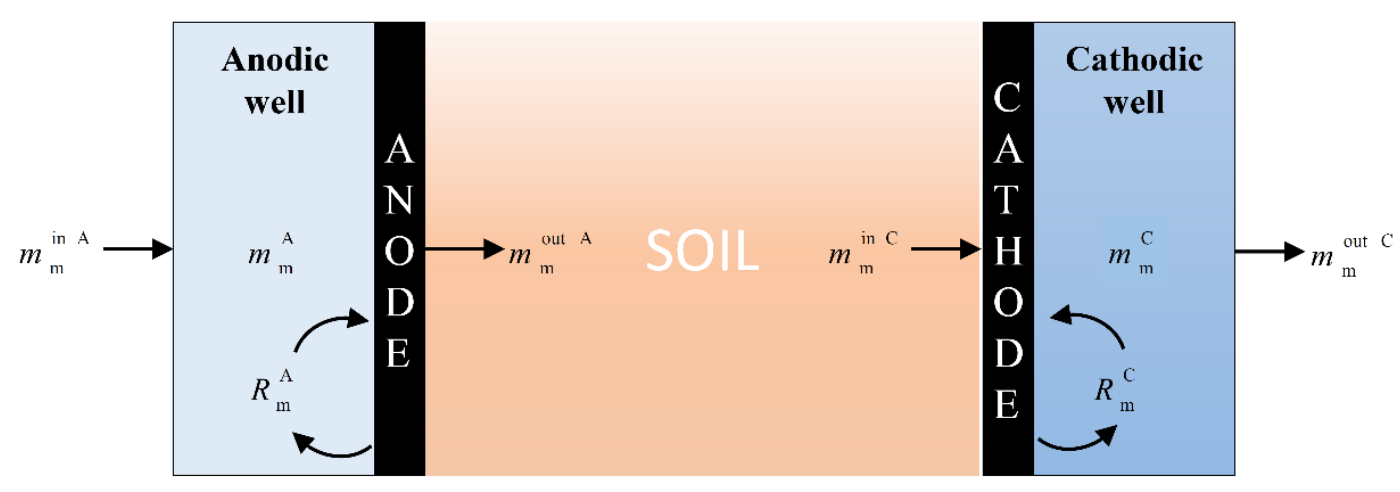

Figure 1. Conceptual model of the one dimensional domain proposed for simulation.

This configuration was chosen because it allows a strictly one-dimensional configuration that facilitates the system model. Additionally, to determine the evolution of the mass of the $M-2$ components in both electrolyte wells, the wells were considered ideal continuous stirred tank reactors, and M-2 additional mass balance equations were formulated for each well, which have the following common expression for both the anode and the cathode:

$\frac{\partial M_{\mathrm{m}}^{*}}{\partial t}=\dot{M}_{\mathrm{m}}^{\mathrm{in}, *}-\dot{M}_{\mathrm{m}}^{\mathrm{out}, *}+R_{\mathrm{m}}^{*}$

where the * superscript is equal to $A$ for the anode and $C$ for the cathode, $M_{\mathrm{m}}$ corresponds to the total mass of component $m(\mathrm{~mol}), \dot{M}_{\mathrm{m}}$ is the mass input rate (superscript in) or mass output rate (superscript out) in the well of component $m\left(\mathrm{~mol} \mathrm{~s}^{-1}\right)$, and $R_{\mathrm{m}}$ is the rate of production or consumption of the component $\left(\mathrm{mol} \mathrm{s}^{-1}\right)$, which is calculated via Faraday's law for those components that have electrochemical reactions. Consequently, we have:

$$
\begin{aligned}
& M_{\mathrm{m}}^{\mathrm{A}}=\rho_{\mathrm{w}} \cdot V^{\mathrm{A}} \cdot C_{\mathrm{m}}^{\mathrm{A}} \\
& \dot{M}_{\mathrm{m}}^{\mathrm{in}}=\rho_{\mathrm{w}} \cdot C_{\mathrm{m}}^{\mathrm{oA}} \cdot \int_{\partial \Omega}\left(-\mathbf{q}_{\mathrm{w}} \cdot \mathbf{n}\right) \cdot d S^{\mathrm{A}}
\end{aligned}
$$




$$
\begin{aligned}
& \dot{M}_{\mathrm{m}}^{\mathrm{outA}}=\int_{\partial \Omega}\left(-\mathbf{l}_{\mathrm{m}} \cdot \mathbf{n}\right) \cdot d S^{\mathrm{A}} \\
& \dot{M}_{\mathrm{m}}^{\mathrm{in} A}=\rho_{\mathrm{w}} \cdot C_{\mathrm{m}}^{\mathrm{oA}} \cdot \int_{\partial \Omega}\left(-\mathbf{q}_{\mathrm{w}} \cdot \mathbf{n}\right) \cdot d S^{A}
\end{aligned}
$$

and at the cathodic well:

$$
\begin{aligned}
& M_{\mathrm{m}}^{\mathrm{C}}=\rho_{\mathrm{w}} \cdot V^{\mathrm{C}} \cdot C_{\mathrm{m}}^{\mathrm{C}} \\
& \dot{M}_{\mathrm{m}}^{\mathrm{inC}}=\int_{\partial \Omega}\left(\mathbf{I}_{\mathrm{m}} \cdot \mathbf{n}\right) \cdot d S^{\mathrm{C}} \\
& \dot{M}_{\mathrm{m}}^{\text {outC }}=\rho_{\mathrm{w}} \cdot C_{\mathrm{m}}^{\mathrm{C}} \cdot \int_{\partial \Omega}\left(\mathbf{q}_{\mathrm{w}} \cdot \mathbf{n}\right) \cdot d S^{\mathrm{C}} \\
& R_{\mathrm{m}}^{\mathrm{C}}=\frac{\varphi_{\mathrm{m}}^{\mathrm{C}}}{F} \cdot \int_{\partial \Omega}(-\mathbf{i} \cdot \mathbf{n}) \cdot d S^{\mathrm{C}}
\end{aligned}
$$

where $V$ is the volume of the electrolyte in the well $\left(\mathrm{m}^{3}\right), S$ is the active electrode surface $\left(\mathrm{m}^{2}\right), C_{\mathrm{m}}^{\mathrm{A}}$ and $C_{\mathrm{m}}^{\mathrm{C}}$ are the total molal concentrations of component $m$ in the anolyte and catholyte, respectively, $C_{\mathrm{m}}^{\mathrm{o}}$ is the total initial molal concentration, $\mathbf{n}$ is the vector normal to the surface of the contact between the soil and the electrolyte well, and $\varphi_{\mathrm{m}}$ is the ratio between the number of moles of component $m$ generated electrochemically and the number of moles of electrons exchanged in the redox half reaction. This study considers the redox reactions related to water electrolysis, which generate $\mathrm{H}^{+}$at the anode via Eq. 1 and $\mathrm{OH}^{-}$at the cathode via Eq. 2; therefore, $\varphi_{H^{+}}^{A}=\varphi_{O H^{-}}^{C}=1$.

\subsection{Chemical speciation equations.}

The calculation of chemical speciation is based on solving a system of $M$ nonlinear equations of the type:

$C_{\mathrm{m}}-C_{\mathrm{m}}^{\mathrm{cal}}=0$ 
where the concentrations $C_{\mathrm{m}}$ are the variables of state of the equilibrium equations described above, and $C_{\mathrm{m}}^{\mathrm{cal}}$ is calculated via the expression:

$$
C_{\mathrm{m}}^{\mathrm{cal}}=\sum_{\mathrm{i}=1}^{\mathrm{N}} \alpha_{\mathrm{i}}^{\mathrm{m}} \cdot c_{\mathrm{i}}=\sum_{\mathrm{i}=1}^{\mathrm{N}} \alpha_{\mathrm{i}}^{\mathrm{m}} \cdot \frac{a_{\mathrm{i}}}{\gamma_{\mathrm{i}}}
$$

where $\alpha_{\mathrm{i}}^{\mathrm{m}}$ is the molar contribution of species $i$ to component $m$. This contribution is equal to the stoichiometry coefficient of component $m$ in the formation reaction of species $i$ and is positive if $m$ is a reactant and negative if $m$ is a product of the production reaction of species $i$. For example, in the water dissociation reaction, $\mathrm{H}_{2} \mathrm{O}$ and $\mathrm{H}^{+}$are the components, and $\mathrm{OH}^{-}$is the species obtained from their combination; therefore, $\alpha_{\mathrm{OH}^{-}}^{\mathrm{H}_{2} \mathrm{O}}=1$ and $\alpha_{O H^{-}}^{H^{+}}=-1$

The activity of each species $i, a_{\mathrm{i}}$, is calculated via the generic chemical equilibrium equation:

$$
\log \left(a_{\mathrm{i}}\right)=\log \left(K_{\mathrm{i}}^{\mathrm{eq}}\right)+\sum_{\mathrm{m}=1}^{\mathrm{M}}\left(\alpha_{\mathrm{i}}^{\mathrm{m}} \cdot \log \left(a_{\mathrm{m}}\right)\right)
$$

where $K_{\mathrm{i}}^{\mathrm{eq}}$ is the equilibrium constant of the formation reaction of $i$. Moreover, $\gamma_{\mathrm{i}}$ is the coefficient of activity that corresponds to each species $i$, which is estimated via the WATEQ Debye Hückel formulation [34].

For chemical speciation, three additional equations are necessary to calculate the water activity $\left(a_{\mathrm{H}_{2} \mathrm{O}}^{\mathrm{cal}}\right)$, the concentration of free chlorine ions $\left(c_{\mathrm{Cl}^{\mathrm{I}}}^{\mathrm{cal}}\right)$ and the ionic strength $\left(I^{\mathrm{cal}}\right.$ ) :

$$
\begin{aligned}
& \log \left(a_{\mathrm{H}_{2} \mathrm{O}}\right)-\log \left(a_{\mathrm{H}_{2} \mathrm{O}}^{\mathrm{cal}}\right)=0 \\
& c_{\mathrm{Cl}}-c_{\mathrm{Cl}}^{\mathrm{cal}}=0
\end{aligned}
$$


$I-I^{c a l}=0$

where the activity of water $\left(a_{\mathrm{H}_{2} \mathrm{O}}^{\text {cal }}\right)$ is obtained via the Garrels and Christ formulation [35]:

$a_{\mathrm{H}_{2} \mathrm{O}}^{\mathrm{cal}}=1-0.017 \cdot \sum_{\mathrm{i}=1}^{\mathrm{N}-\mathrm{H}_{2} \mathrm{O}} c_{\mathrm{i}}$

The activity of the free chlorine ion $\left(a_{\mathrm{Cl}}^{\mathrm{cal}}\right)$ is calculated by applying the electroneutrality principle:

$a_{\mathrm{Cl}}^{\mathrm{cal}}=\gamma_{\mathrm{Cl}^{-}} \cdot c_{\mathrm{Cl}}^{\mathrm{cal}}=-\frac{\gamma_{\mathrm{Cl}^{-}}}{z_{\mathrm{Cl}^{-}}} \cdot \sum_{\mathrm{i}=1}^{\mathrm{N}-\mathrm{Cl}^{-}} z_{\mathrm{i}} \cdot c_{\mathrm{i}}$

Finally, $I^{\text {cal }}$ is obtained via:

$I^{\mathrm{cal}}=\frac{1}{2} \cdot \sum_{\mathrm{i}=1}^{\mathrm{N}} z_{\mathrm{i}}^{2} \cdot c_{\mathrm{i}}$

The variables $a_{\mathrm{m}}, a_{\mathrm{H}_{2} \mathrm{O}}^{\mathrm{cal}}, c_{\mathrm{Cl}^{-}}$and $I$ are the unknowns of the system of algebraic equations that must be solved to obtain the speciation of the porewater.

\subsection{Numerical implementation}

The M4EKR model was implemented in Comsol Multiphysics [36], which is a partial differential equation solver based on the application of the finite element method with Lagrange multipliers. The "multiphysics" capability was used without the preprogrammed modules provided by the software. Thus, both differential and algebraic equations to be solved were defined using constitutive models to consider the initial conditions and the boundary conditions imposed. This was possible due to the versatility and adaptability of this type of program based on a multiphysics environment [37-39]. In addition, the automatic differentiation techniques [40] included in some programs, such as Comsol Multiphysics, provide symbolic expressions to define the iteration matrix [41], 
which improves the convergence behaviour of the model and allows the complexity of the problem to increase while maintaining solution efficiency[42, 43]. Thus, in the proposed extended geochemical model, we defined 9 partial differential equations (mass balance in the soil), 16 ordinary differential equations (mass balance in the electrolyte wells), and 11 algebraic equations (chemical speciation), which yields a total of 36 state variables to be solved in each time step. In the simplified model, 4 partial differential equations, 4 ordinary differential equations and 11 algebraic equations were solved to yield 18 state variables.

\section{SIMULATION OF EKR PROCESS}

\subsection{Modelled configuration.}

An EKR process of a natural soil from an area near a clay quarry in Spain was studied. According to the Unified Soil Classification System, the soil is a low plasticity clay (CL), whilst according to the texture classification of the United States Department of Agriculture (USDA), it is a silty loam [44]. Table 1 shows the mineralogical and textural parameters of the material. A natural density of $1.89 \mathrm{~g} / \mathrm{cm}^{3}$ and a gravimetric water content of $32.8 \%$ were assumed to reproduce realistic compaction conditions [44]. Under these compaction conditions, it was reasonable to hypothesise that the soil deformability is negligible. The hydraulic behaviour was characterised by oedometric tests and by the use of a chilled-mirror psychrometer [45] to obtain the retention curve. Table 2 shows the obtained parameters. 
Table 1. Textural and mineralogical of modeled soil.

\begin{tabular}{cc}
\hline Size fraction & Mass percentage (\%) \\
\hline Sand & 26.9 \\
Silt & 68.2 \\
Clay & 4.9 \\
\hline Mineral & Mass percentage (\%) \\
\hline Quartz & 7 \\
Feldspar & 15 \\
Calcite & 4 \\
Kaolinite & 26 \\
Smectite & 28 \\
Illite & 20 \\
\hline
\end{tabular}

Table 2. Soil hydraulic parameters.

\begin{tabular}{c|c|c} 
Parameters & Values & Units \\
\hline$\alpha_{\mathrm{VG}}$ & 0.0147 & $\mathrm{kPa}^{-1}$ \\
$n_{\mathrm{VG}}$ & 1.2593 & - \\
$m_{\mathrm{VG}}$ & 0.2059 & - \\
$\phi$ & 0.4681 & - \\
$K_{\mathrm{sat}}^{\mathrm{h}}$ & $2.03 \times 10^{-10}$ & $\mathrm{~m} \mathrm{~s}^{-1}$ \\
$K_{\mathrm{sat}}^{\mathrm{eo}}$ & $2.4 \times 10^{-9}$ & $\mathrm{~m}^{2} \mathrm{~V}^{-1} \mathrm{~s}^{-1}$ \\
$\rho_{s}$ & 2681.5 & $\mathrm{~kg} \mathrm{~m}^{-3}$ \\
$\delta_{\mathrm{i}}^{\mathrm{L}}$ & 0.01 & $\mathrm{~m}$ \\
$\tau$ & 1.00 & - \\
\hline
\end{tabular}

Figure 2 shows the dimensions of the experimental setup. The electrokinetic reactor is composed of a $15 \times 15 \times 3 \mathrm{~cm}$ central compartment that houses the soil to be treated and two side compartments with dimensions of $15 \times 3 \times 3 \mathrm{~cm}$ that are used as electrolyte wells, in which the electrodes are located. The electrodes have a prismatic geometry with an electrochemically active surface equal to the well/soil interface $\left(S^{\mathrm{A}}=S^{\mathrm{C}}=45 \mathrm{~cm}^{2}\right)$. The 
electrolyte volume in the wells is assumed to be constant throughout the simulation process $\left(V^{\mathrm{A}}=V^{\mathrm{C}}=135 \mathrm{~cm}^{3}\right)$.

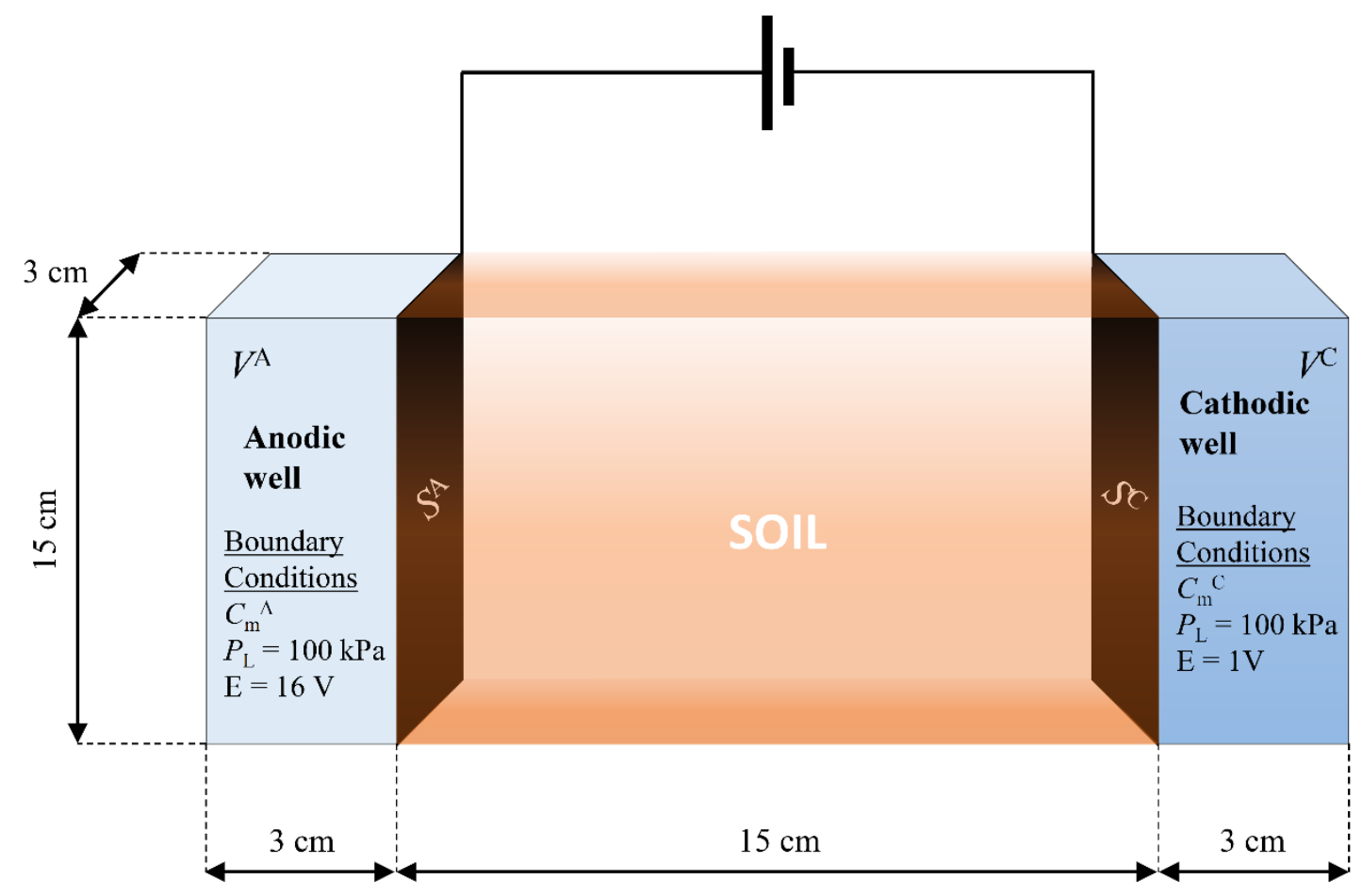

Figure 2. Dimensions and boundary conditions of the modeled system.

Table 3 shows the $M$ components and $N$ species that make up the two geochemical models, including the extended geochemical model (EGM) and the simplified geochemical model (SGM). The equilibrium reactions, their thermodynamic constants [46] and the physicochemical properties of each species are also shown. The values of the binary diffusion coefficients in water of each species were not found in the literature, so they were estimated using the expression of Pikal [47]. 
Table 3. Thermodynamical properties of the modelled geochemical systems.

EGM components: $\mathrm{Cl}^{-}, \mathrm{H}_{2} \mathrm{O}, \mathrm{H}^{+} \mathrm{CO}_{3}^{-2}, \mathrm{SO}_{4}^{-2}, \mathrm{NH}_{4}^{+}, \mathrm{Ca}^{+2}, \mathrm{Mg}^{+2}, \mathrm{Na}^{+}$and $\mathrm{K}^{+}$.

SGM components: $\mathrm{Cl}^{-}, \mathrm{H}_{2} \mathrm{O}, \mathrm{H}^{+}, \mathrm{Na}^{+}$.

\begin{tabular}{|c|c|c|c|c|c|}
\hline Species & Reactions & $\begin{array}{l}\log K_{\mathrm{i}}^{\mathrm{eq}} \\
\left(25^{\circ} \mathrm{C}\right)\end{array}$ & $\begin{array}{c}\text { Hard core } \\
\text { diameter / } \\
\AA\end{array}$ & $D_{\mathrm{i}}{ }^{0} / \mathbf{m}^{2} \mathbf{s}^{-1}$ & $\begin{array}{l}\text { Used in the } \\
\text { geochemical } \\
\text { model }\end{array}$ \\
\hline $\mathrm{Cl}^{-}$ & $\mathrm{Cl}^{-}$ & 0 & 3.6 & $2.03 \times 10^{-9}$ & EGM/SGM \\
\hline $\mathrm{H}_{2} \mathrm{O}$ & $\mathrm{H}_{2} \mathrm{O}$ & 0 & 3.4 & $5.27 \times 10^{-9}$ & EGM/SGM \\
\hline $\mathrm{H}^{+}$ & $\mathrm{H}^{+}$ & 0 & 4.1 & $9.31 \times 10^{-9}$ & EGM/SGM \\
\hline $\mathrm{CO}_{3}{ }^{-2}$ & $\mathrm{CO}_{3}{ }^{-2}$ & 0 & 4.7 & $9.55 \times 10^{-10}$ & EGM \\
\hline $\mathrm{SO}_{4}^{-2}$ & $\mathrm{SO}_{4}^{-2}$ & 0 & 4.7 & $1.07 \times 10^{-9}$ & EGM \\
\hline $\mathrm{NH}_{4}{ }^{+}$ & $\mathrm{NH}_{4}{ }^{+}$ & 0 & 4.1 & $1.98 \times 10^{-9}$ & EGM \\
\hline $\mathrm{Ca}^{+2}$ & $\mathrm{Ca}^{+2}$ & 0 & 5.7 & $7.93 \times 10^{-10}$ & EGM \\
\hline $\mathrm{Mg}^{+2}$ & $\mathrm{Mg}^{+2}$ & 0 & 5.7 & $7.05 \times 10^{-10}$ & EGM \\
\hline $\mathrm{Na}^{+}$ & $\mathrm{Na}^{+}$ & 0 & 4.1 & $1.33 \times 10^{-9}$ & EGM/SGM \\
\hline $\mathrm{K}^{+}$ & $\mathrm{K}^{+}$ & 0 & 4.1 & $1.96 \times 10^{-9}$ & EGM \\
\hline $\mathrm{OH}^{-}$ & $\mathrm{H}_{2} \mathrm{O} \leftrightarrow \mathrm{OH}^{-}+\mathrm{H}^{+}$ & -14 & 3.6 & $5.27 \times 10^{-9}$ & EGM/SGM \\
\hline $\mathrm{HCO}_{3}^{-}$ & $\mathrm{CO}_{3}^{-2}+\mathrm{H}^{+} \leftrightarrow \mathrm{HCO}_{3}^{-}$ & 10.33 & 3.6 & $1.18 \times 10^{-9}$ & EGM \\
\hline $\mathrm{H}_{2} \mathrm{CO}_{3}{ }^{*}$ & $\mathrm{CO}_{3}{ }^{-2}+2 \mathrm{H}^{+} \leftrightarrow \mathrm{H}_{2} \mathrm{CO}_{3}{ }^{*}$ & 16.68 & 3.4 & $1.92 \times 10^{-9}$ & EGM \\
\hline $\mathrm{HSO}_{4}^{-}$ & $\mathrm{SO}_{4}^{-2}+\mathrm{H}^{+} \leftrightarrow \mathrm{HSO}_{4}^{-}$ & 1.98 & 3.6 & $1.33 \times 10^{-9}$ & EGM \\
\hline $\mathrm{NH}_{3}$ & $\mathrm{NH}_{4}^{+} \leftrightarrow \mathrm{NH}_{3}+\mathrm{H}^{+}$ & -9.23 & 3.4 & $2.00 \times 10^{-9}$ & EGM \\
\hline $\mathrm{CaHCO}_{3}{ }^{+}$ & $\mathrm{Ca}^{+2}+\mathrm{CO}_{3}^{-2}+\mathrm{H}^{+} \leftrightarrow \mathrm{CaHCO}_{3}^{+}$ & 11.43 & 4.1 & $5.06 \times 10^{-10}$ & EGM \\
\hline $\mathrm{CaCO}_{3}$ & $\mathrm{Ca}^{+2}+\mathrm{CO}_{3}^{-2} \leftrightarrow \mathrm{CaCO}_{3}$ & 3.22 & 3.4 & $4.46 \times 10^{-10}$ & EGM \\
\hline $\mathrm{CaSO}_{4}$ & $\mathrm{Ca}^{+2}+\mathrm{SO}_{4}^{-2} \leftrightarrow \mathrm{CaSO}_{4}$ & 2.31 & 3.4 & $4.71 \times 10^{-10}$ & EGM \\
\hline $\mathrm{Ca}(\mathrm{OH})^{+}$ & $\mathrm{Ca}^{+2}+\mathrm{H}_{2} \mathrm{O} \leftrightarrow \mathrm{Ca}(\mathrm{OH})^{+}+\mathrm{H}^{+}$ & -12.78 & 4.1 & $2.13 \times 10^{-10^{*}}$ & EGM \\
\hline $\mathrm{MgHCO}_{3}{ }^{+}$ & $\begin{array}{l}\mathrm{Mg}^{+2}+\mathrm{H}^{+}+\mathrm{CO}_{3}^{-2} \leftrightarrow \\
\mathrm{MgHCO}_{3}{ }^{+}\end{array}$ & 11.37 & 4.1 & $4.78 \times 10^{-10}$ & EGM \\
\hline $\mathrm{MgCO}_{3}$ & $\mathrm{Mg}^{+2}+\mathrm{CO}_{3}^{-2} \leftrightarrow \mathrm{MgCO}_{3}$ & 2.98 & 3.4 & $4.21 \times 10^{-10}$ & EGM \\
\hline $\mathrm{MgSO}_{4}$ & $\mathrm{Mg}^{+2}+\mathrm{SO}_{4}^{-2} \leftrightarrow \mathrm{MgSO}_{4}$ & 2.23 & 3.4 & $4.45 \times 10^{-10}$ & EGM \\
\hline $\mathrm{Mg}(\mathrm{OH})^{+}$ & $\mathrm{Mg}^{+2}+\mathrm{H}_{2} \mathrm{O} \leftrightarrow \mathrm{Mg}(\mathrm{OH})^{+}+\mathrm{H}^{+}$ & -11.68 & 4.1 & $2.13 \times 10^{-10^{*}}$ & EGM \\
\hline $\mathrm{NaHCO}_{3}$ & $\mathrm{Na}^{+}+\mathrm{HCO}_{3}^{-} \leftrightarrow \mathrm{NaHCO}_{3}$ & 10.08 & 3.4 & $6.73 \times 10^{-10}$ & EGM \\
\hline $\mathrm{NaCO}_{3}{ }^{-}$ & $\mathrm{Na}^{+}+\mathrm{CO}_{3}^{-2} \leftrightarrow \mathrm{NaCO}_{3}^{-}$ & 1.27 & 3.6 & $5.85 \times 10^{-10}$ & EGM \\
\hline $\mathrm{NaSO}_{4}^{-}$ & $\mathrm{Na}^{+}+\mathrm{SO}_{4}^{-2} \leftrightarrow \mathrm{NaSO}_{4}^{-}$ & 0.94 & 3.6 & $6.18 \times 10^{-10}$ & EGM \\
\hline $\mathrm{NaOH}$ & $\mathrm{Na}^{+}+\mathrm{H}_{2} \mathrm{O} \leftrightarrow \mathrm{NaOH}+\mathrm{H}^{+}$ & -14.75 & 3.4 & $1.89 \times 10^{-10^{*}}$ & EGM/SGM \\
\hline $\mathrm{KSO}_{4}^{-}$ & $\mathrm{K}^{+}+\mathrm{SO}_{4}^{-2} \leftrightarrow \mathrm{KSO}_{4}^{-}$ & 0.88 & 3.6 & $7.46 \times 10^{-10}$ & EGM \\
\hline $\mathrm{KOH}$ & $\mathrm{K}^{+}+\mathrm{H}_{2} \mathrm{O} \leftrightarrow \mathrm{KOH}+\mathrm{H}^{+}$ & -14.46 & 3.4 & $1.89 \times 10^{-10^{*}}$ & EGM \\
\hline $\mathrm{MgCl}^{+}$ & $\mathrm{Mg}^{+2}+\mathrm{Cl}^{-} \leftrightarrow \mathrm{MgCl}^{+}$ & 0.35 & 4.1 & $2.13 \times 10^{-10^{*}}$ & EGM \\
\hline $\mathrm{CaCl}^{+}$ & $\mathrm{Ca}^{+2}+\mathrm{Cl}^{-} \leftrightarrow \mathrm{CaCl}^{+}$ & -0.29 & 4.1 & $2.13 \times 10^{-10^{*}}$ & EGM \\
\hline $\mathrm{KCl}$ & $\mathrm{K}^{+}+\mathrm{Cl}^{-} \leftrightarrow \mathrm{KCl}$ & -0.5 & 3.4 & $1.89 \times 10^{-10^{*}}$ & EGM \\
\hline $\mathrm{NaCl}$ & $\mathrm{Na}^{+}+\mathrm{Cl}^{-} \leftrightarrow \mathrm{NaCl}$ & -0.5 & 3.4 & $1.89 \times 10^{-10^{*}}$ & EGM/SGM \\
\hline $\mathrm{CaCl}_{2}$ & $\mathrm{Ca}^{+2}+2 \mathrm{Cl}^{-} \leftrightarrow \mathrm{CaCl}_{2}$ & -0.64 & 3.4 & $7.54 \times 10^{-10}$ & EGM \\
\hline
\end{tabular}

* Obtained by using Pikal's model [46] 
Table 4 shows the initial conditions of the problems simulated in this study. The compositions of the electrolyte and porewater used in the EGM were defined from a local sample of groundwater with a significant carbonate concentration [48]. Two criteria were followed to determine the analogous composition employed in the SGM simulation: the same initial $\mathrm{pH}$ (7.6) and the same concentration of positive charges in the initial state.

Figure 2 shows the boundary conditions applied in the simulations.

Table 4. Initial conditions.

\begin{tabular}{|c|c|c|c|c|c|c|c|c|c|c|c|}
\hline \multicolumn{3}{|c|}{ Total Concentration* } & \multicolumn{3}{|c|}{ Chemical Speciation } & \multicolumn{3}{|c|}{ Hydraulic } & \multicolumn{3}{|c|}{ Electrical } \\
\hline molal & EGM & SGM & molal & EGM & SGM & $\mathbf{k P a}$ & EGM & SGM & $\mathbf{v}$ & EGM & SGM \\
\hline$C_{\mathrm{H}^{+}}$ & $3.04 \times 10^{-3}$ & $-4.18 \times 10^{-7}$ & $a_{\mathrm{H}^{+}}$ & $2.51 \times 10^{-8}$ & $2.51 \times 10^{-8}$ & $P_{\mathrm{L}}$ & 100 & 100 & $E$ & 1 & 1 \\
\hline$C_{\mathrm{CO}_{3}^{-2}}$ & $2.93 \times 10^{-3}$ & 0 & $a_{\mathrm{CO}_{3}^{-2}}$ & $4.41 \times 10^{-6}$ & 0 & & & & & & \\
\hline$C_{\mathrm{SO}_{4}^{-2}}$ & $1.13 \times 10^{-3}$ & 0 & $a_{\mathrm{SO}_{4}^{-2}}$ & $5.25 \times 10^{-4}$ & 0 & & & & & & \\
\hline$C_{\mathrm{NH}_{4}^{+}}$ & $2.77 \times 10^{-6}$ & 0 & $a_{\mathrm{NH}_{4}^{+}}$ & $2.39 \times 10^{-6}$ & 0 & & & & & & \\
\hline$C_{\mathrm{Ca}^{+2}}$ & $2.30 \times 10^{-3}$ & 0 & $a_{\mathrm{Ca}^{+2}}$ & $1.29 \times 10^{-3}$ & 0 & & & & & & \\
\hline$C_{\mathrm{Mg}^{+2}}$ & $2.06 \times 10^{-3}$ & 0 & $a_{\mathrm{Mg}^{+2}}$ & $1.17 \times 10^{-3}$ & 0 & & & & & & \\
\hline$C_{\mathrm{Na}^{+}}$ & $3.58 \times 10^{-3}$ & $1.17 \times 10^{-2}$ & $a_{\mathrm{Na}^{+}}$ & $3.13 \times 10^{-3}$ & $1.05 \times 10^{-2}$ & & & & & & \\
\hline$C_{\mathrm{K}^{+}}$ & $5.31 \times 10^{-5}$ & 0 & $a_{\mathrm{K}^{+}}$ & $4.65 \times 10^{-5}$ & 0 & & & & & & \\
\hline & & & $a_{\mathrm{H}_{2} \mathrm{O}}$ & $9.99 \times 10^{-1}$ & $9.99 \times 10^{-1}$ & & & & & & \\
\hline & & & $c_{\mathrm{Cl}^{-}}$ & $7.24 \times 10^{-3}$ & $1.17 \times 10^{-2}$ & & & & & & \\
\hline & & & $I$ & $1.66 \times 10^{-2}$ & $1.17 \times 10^{-2}$ & & & & & & \\
\hline
\end{tabular}

*Concentration of liquid pore and electrolytes (anolyte and catholyte)

\subsection{EGM simulation}

To assess the scope of the M4EKR model, the EKR process was simulated with the EGM described in Section 2 for a total test time of 3 days. Figure 3 shows the spatial distribution of a set of variables of interest for different times. 

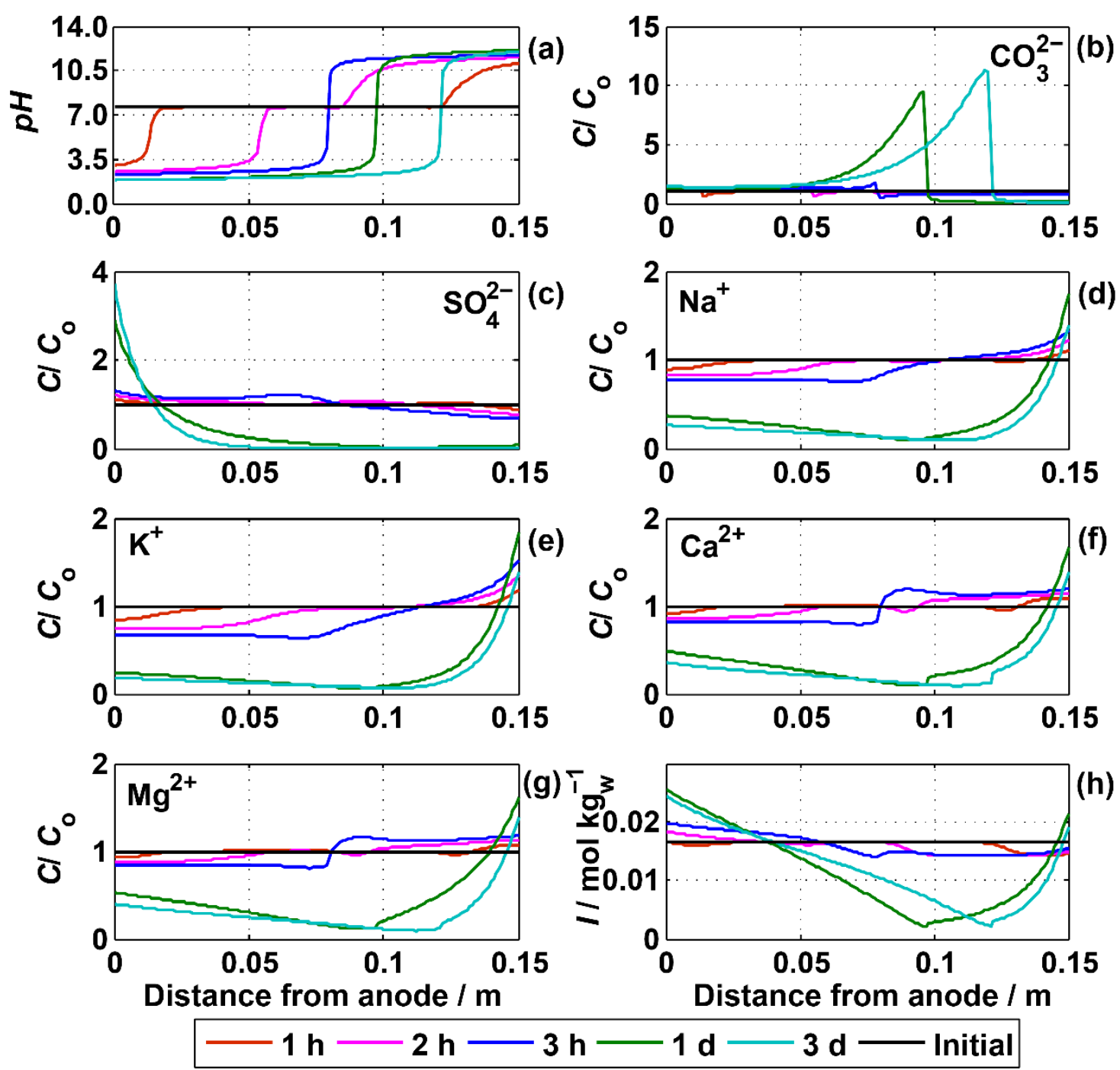

Figure 3. Spatial distribution in the EGM at selected times of (a) $p H$; (b) total normalised concentration of the $\mathrm{CO}_{3}^{2-}$ component; (c) total normalised concentration of the $\mathrm{SO}_{4}^{2-}$ component; (d) total normalised concentration of the $\mathrm{Na}^{+}$component; (e) total normalised concentration of the $\mathrm{K}^{+}$component; (f) total normalised concentration of the $\mathrm{Ca}^{2+}$ component; (g) total normalised concentration of the $\mathrm{Mg}^{2+}$ component; (h) Ionic strength, $I$.

The $\mathrm{pH}$ distribution follows the typical pattern described in the literature $[14,23]$, including an acidic front and a basic front that move towards the centre of the domain from the anodic and cathodic wells, respectively (Figure 3a). Both are located in a central 
position (although closer to the cathode due to the higher ionic mobility of $\mathrm{H}^{+}$), and the resulting front moves slowly to the position of the cathode well. The behaviours of different ions are similar to what is expected theoretically (Figures $3 \mathrm{~b}$ to $3 \mathrm{~g}$ ). Thus, increased concentrations of the anionic and cationic components form near the anode and the cathode, respectively, which causes long-term increases in the ionic strengths with respect to the initial values in these zones (Figure 3h). Supplementary Figure SM 1 shows the temporal evolution of the variables in Figure 3 for the solutions contained in the anode and cathode wells; the developments are consistent with the expectations.

Two observable phenomena in the ionic distributions are especially interesting. First, in nearly three quarters of the simulated domain, the ionic strength is less than the initial strength after three days of simulation, which shows the progressive desalination system that was shown in the results of other authors [49-51]. Second, the $\mathrm{CO}_{3}^{2-}$ component has an anomalous distribution with a significant concentration peak in the centre of the domain and not at the anode, as would be expected for an anion. In the equilibrium of carbonates in a closed system [52], the bicarbonate ion, $\mathrm{HCO}_{3}^{-}$, only is predominant at $\mathrm{pH}$ values between 6.3 and 10.25. Behind the basic front, the main species is the carbonate ion $\left(\mathrm{CO}_{3}^{2-}\right)$, and behind the acidic front is predominant species is $\mathrm{H}_{2} \mathrm{CO}_{3}^{*}$ (treated as a non-volatile acid sum of the concentrations of the $\mathrm{H}_{2} \mathrm{CO}_{3}$ acid and the dissolved $\mathrm{CO}_{2}$ ). The modelled behaviour of both $\mathrm{HCO}_{3}^{-}$and $\mathrm{CO}_{3}^{2-}$ is consistent with the distributions of the rest of charged species (Figures $4 \mathrm{a}$ and $4 \mathrm{~b}$, respectively). However, the distribution of carbonic acid $\left(\mathrm{H}_{2} \mathrm{CO}_{3}^{*}\right.$, Figure $\left.4 \mathrm{c}\right)$ causes the total concentration of the carbonates to have the characteristic accumulation before the $\mathrm{pH}$ front (Figure 3b). The reason for this phenomenon can be determined from the various components of the total flow of carbonates. Only the $\mathrm{H}_{2} \mathrm{CO}_{3}^{*}$ species is present in the acidic zone, which does not move 
by electromigration but rather by advective flow of the liquid phase (hydraulic flow and electro-osmotic flow) and by the diffusive/dispersive flux of the species. Moreover, the flow of the carbonates that have a net negative electrical charge $\left(\mathrm{HCO}_{3}^{-}\right.$and $\left.\mathrm{CO}_{3}^{2-}\right)$ is dominated by electromigration. The final profile of the total flux of the $\mathrm{CO}_{3}^{2-}$ component (Figure 4d) is positive from the anode to the $\mathrm{pH}$ front (flow to the right). From the $\mathrm{pH}$ front to the cathode, the total flux is negative (to the left). Because the $\mathrm{pH}$ front determines which secondary species of the family of carbonates is predominant in the solution, it also marks the main type of transport. Thus, the main component of flow in the acidic region is advective-diffusive, and the flow in the basic region is by electromigration. Both flows come together in the front and generate an accumulation zone of the $\mathrm{H}_{2} \mathrm{CO}_{3}^{*}$ species (Figure 4c) and, consequently, of the total $\mathrm{CO}_{3}^{2-}$ component (Figure 3b).
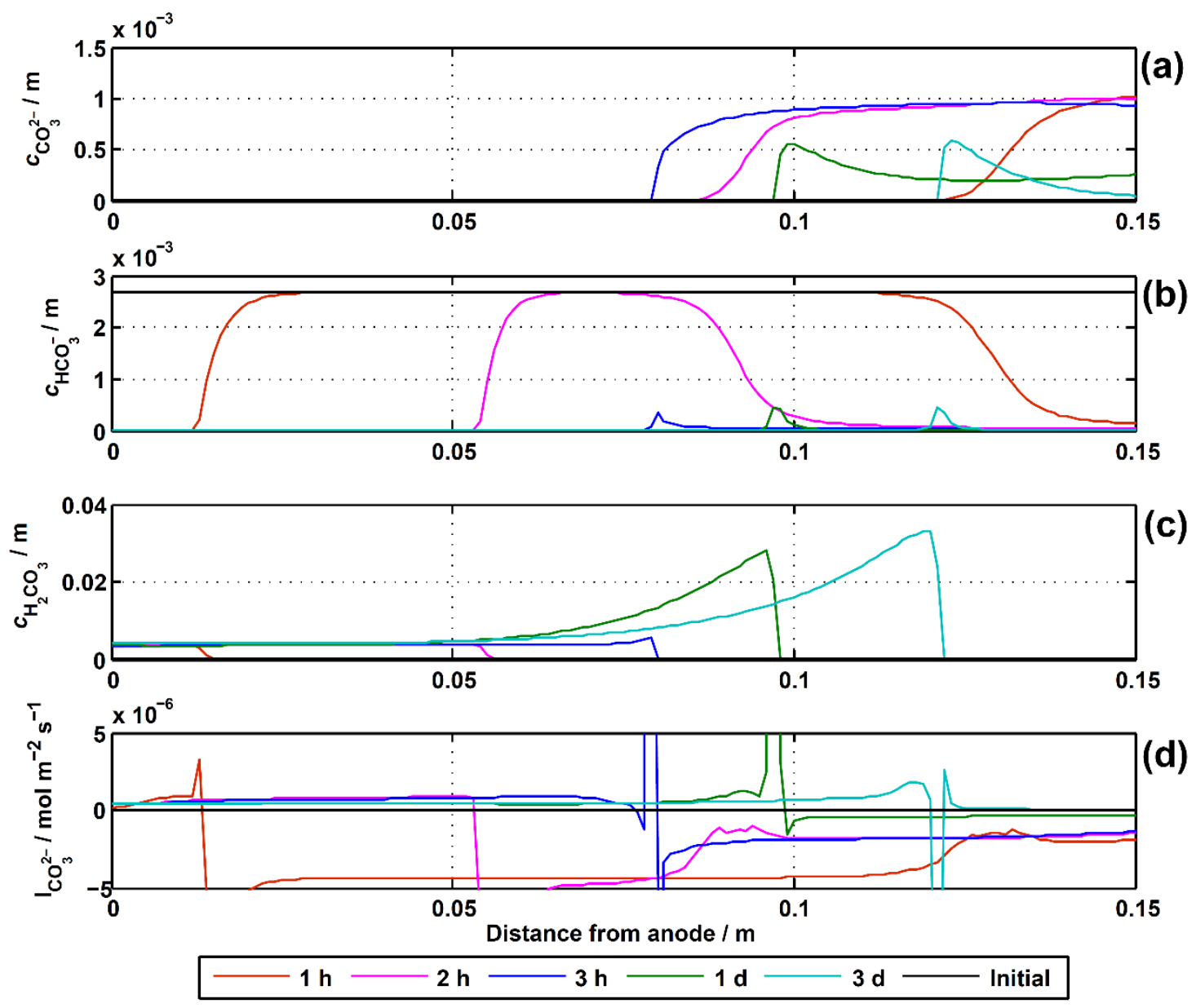
Figure 4. Spatial distribution in the EGM at selected times of (a) molal concentration of the $\mathrm{CO}_{3}^{2-}$ species; (b) molal concentration of the $\mathrm{HCO}_{3}^{-}$species; (c) molal concentration of the $\mathrm{H}_{2} \mathrm{CO}_{3}$ species; (d) total mass flux of the $\mathrm{CO}_{3}^{2-}$ component.

The other state variables of the system, such as the electrical potential and the fluid pressure in soil pores (Figure 5), behave as is expected theoretically and from the experimental results in the literature $[53,54]$. Figure 5a shows that the initial distribution of the electrical potential is nearly linear, but its slope decreases near the anode and cathode and increases in the intermediate zone. This is due to the spatial distribution of the electrical conductivity (Figure 5b), which is high near the electrolyte wells and lower in the centre of the domain due to the redistribution of solutes and the ionic strength (Figure $3 \mathrm{~h}$ ). The liquid pressure decreases rapidly to negative values near the anode, which causes soil desaturation as described in the literature [55, 56]. Over the long term, the entire domain experiences unsaturated conditions due to the reduced hydraulic 
permeability of the soil (clay CL), which leads to partially saturated conditions when the output electro-osmotic flow is greater than the input hydraulic flow.
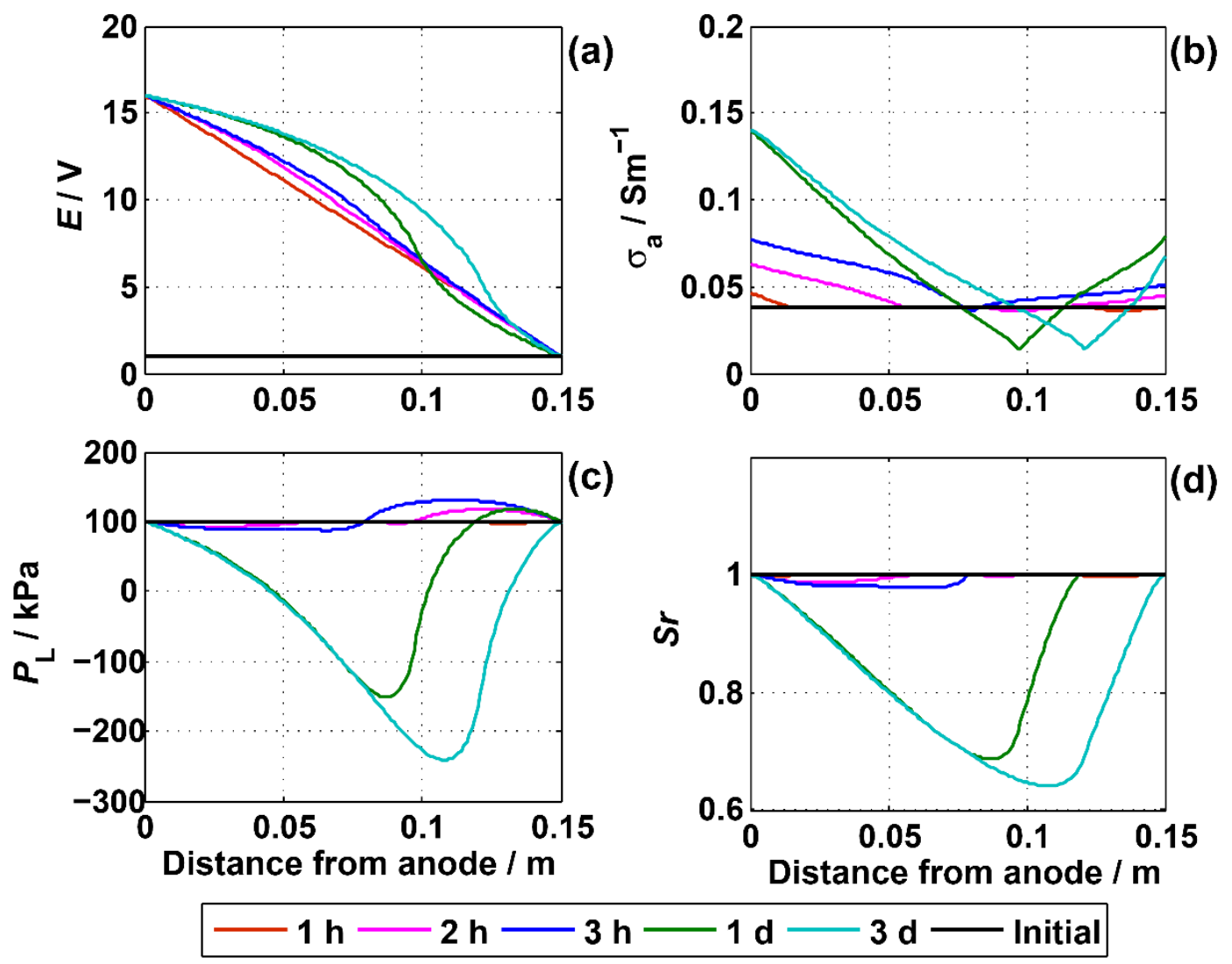

Figure 5. Spatial distribution in the EGM at selected times of (a) electric potential, $E$; (b) apparent electrical conductivity, $\sigma_{\mathrm{a}}$; (c) liquid pressure, $P_{\mathrm{L}}$; (d) degree of saturation, $S r$.

The desaturation process influences the temporal evolution of the outgoing or incoming anode flow to the cathode (Figure 6). Throughout the simulated time interval, the liquid inputs to the cathodic well (outputs from the soil) are greater than the outputs of the anodic well (inputs to the soil). Consequently, desaturation occurs near the anodic well and then spreads to the entire domain, as was discussed in the previous paragraph. When the partially saturated conditions reach the vicinity of the cathodic well, the incoming flow to the well by hydraulic flow decreases to zero and becomes outgoing due to the suction gradient. This compensates for the increased electro-osmotic flow towards the cathode 
well (Figures 5c and 5d). The flows out of the anode and into the cathode equalise, and a steady state is reached. The difference between the values of the electro-osmotic flows, which are always higher near the cathode than near the anode, occurs because the electric conductivity is higher in the latter, the electric potential gradient is lower, and consequently the flow produced by the gradient is also lower.
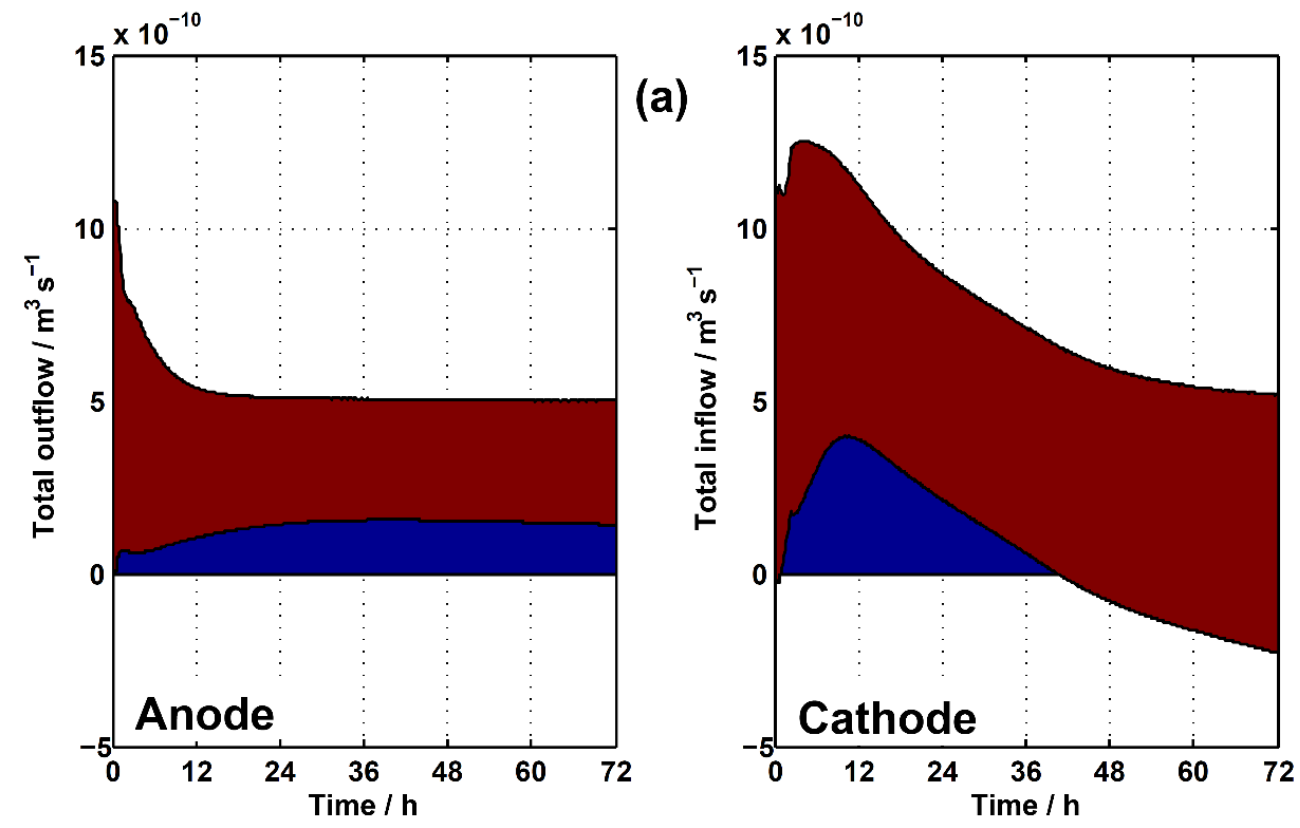

(b)

\begin{tabular}{|l}
$\square y d r a u l i c$ \\
Electroosmotic
\end{tabular}

Figure 6. Total liquid fluxes in the electrolyte wells (a) anodic well outflux (b) cathodic well influx.

\subsection{EGM vs SGM simulations}

The previous section showed that the M4EKR model for the EGM allows the main behaviour of EKR processes in soils to be characterised. However, other authors [13, 14, 48] have also reproduced some of these trends with simpler geochemical models (e.g., desaturation, differences in the decrease in the electrical potential and the electro-osmotic flow). Therefore, the question arises as to whether it is necessary to add complexity to numerical models to correctly simulate EKR in natural soils and porewaters. To 
demonstrate the suitability of this simulation, an SGM simulation is performed to make critical comparisons with the EGM results.

A SGM composed solely of the components $\mathrm{Na}^{+}, \mathrm{Cl}^{-}, \mathrm{H}_{2} \mathrm{O}$ and $\mathrm{H}^{+}$is developed by adopting the parameters in Table 3 and the initial conditions in Table 4. We first compared the $\mathrm{pH}$, which is essential to understanding the speciation in the EGM and to assessing the efficiencies of different physical and chemical processes that take place when these remediation techniques are applied [57]. Figure 7 compares the temporal evolution of the $\mathrm{pH}$ in the anodic and cathodic wells obtained with both geochemical models. In the SGM, the $\mathrm{pH}$ increases by approximately 3.5 at the anode and 2.3 at the cathode in $60 \mathrm{~s}$. However, the variation in the EGM is much slower, and the $\mathrm{pH}$ only reaches the SGM values after $10 \mathrm{~h}$ of simulation. This phenomenon can be explained by the buffer system of carbonates, which is capable of maintaining the $\mathrm{pH}$ at relatively stable values even with small additions of acids or bases. For this reason, the temporal evolutions of both models are markedly different until 10 hours have passed, after which the buffering ceases to have an effect because of the nearly complete disappearance of bicarbonates in the domain. 


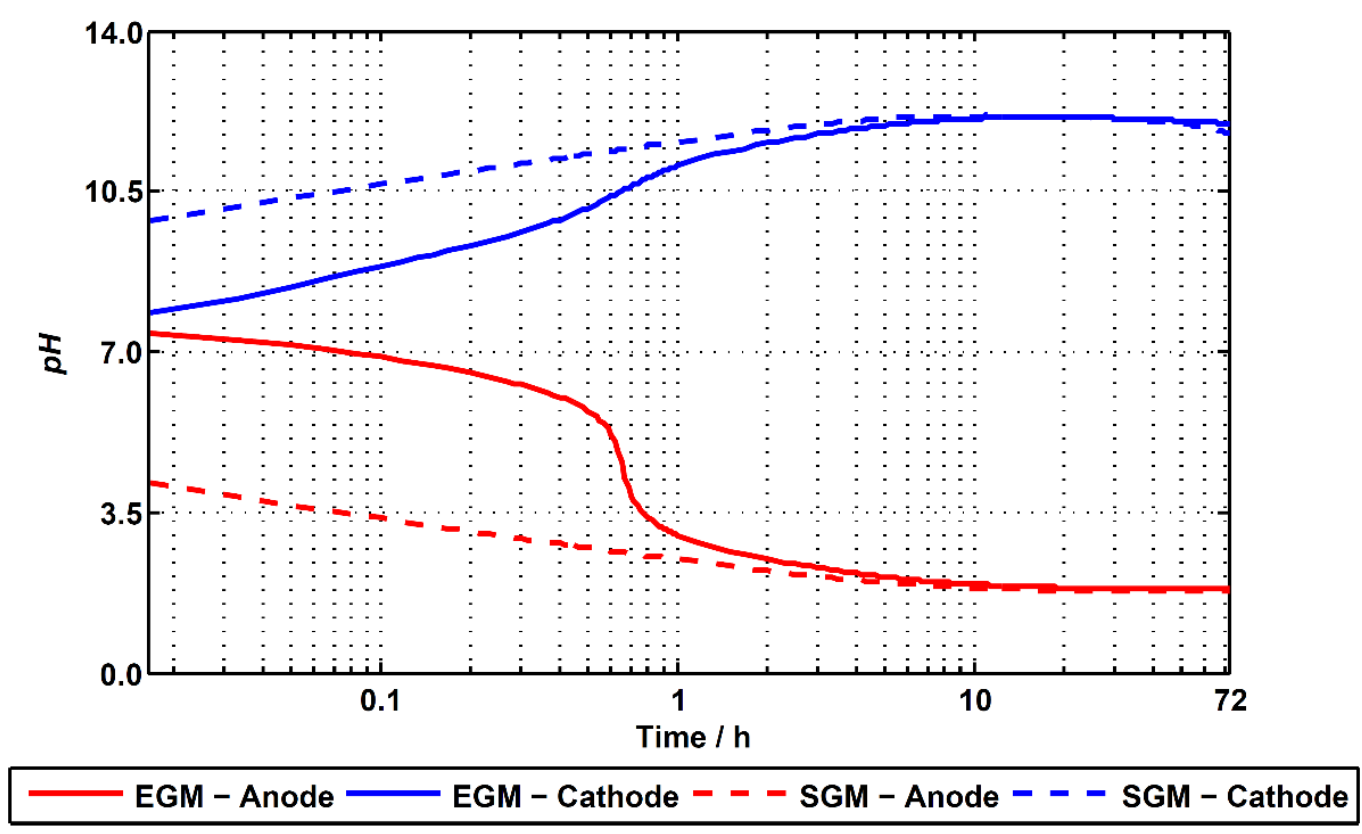

Figure 7. $p H$ evolution in the anodic and cathodic wells in the EGM and the SGM.

If different $\mathrm{pH}$ profiles are observed at various times (Figure 8), the forward speed of the fronts is much faster in the SGM; the front is already well-defined in 1 hour compared to the 3 hours required in the EGM. $\mathrm{H}^{+}$is a conservative solute in the SGM, whereas it is significantly delayed in the EGM due to the buffering effect of the carbonate system. This effect can be seen more clearly with the help of Figure 9. Points A and B represent the mean locations of the acidic and basic fronts within the domain, respectively. Their positions $\left(x_{\mathrm{A}}, x_{\mathrm{B}}\right)$ were calculated using the expressions

$$
\begin{aligned}
& p H\left(x_{A}, t\right)=p H_{\mathrm{ini}}-\Delta p H_{\text {acidic }}(t) / 2 \\
& p H\left(x_{B}, t\right)=p H_{\mathrm{ini}}+\Delta p H_{\text {basic }}(t) / 2
\end{aligned}
$$

where $p H_{\text {ini }}$ is the initial $p H$ value, $t$ the time, and the $p H$ increments where calculated as

$$
\begin{aligned}
& \Delta p H_{\text {acidic }}(t)=p H_{\mathrm{ini}}-p H_{\min }(t) \\
& \Delta p H_{\text {basic }}(t)=p H_{\text {max }}(t)-p H_{\mathrm{ini}}
\end{aligned}
$$


where $p H_{\max }(t)$ and $p H_{\min }(t)$ are the maximum and minimum values of the $\mathrm{pH}$ profile at time $t$. Initially, the points A and B are located in the extremes of the domain, but when the $\mathrm{pH}$ front is fully formed, their positions are nearly coincident. If the evolution of the positions of the fronts is represented by the locations of these points, the disparity in the speeds of advancement of the fronts can also be observed (Figure 10). In the EGM, the advancement of the acidic front is nearly zero until $1 \mathrm{~h}$ has elapsed, whereas in the SGM, the $\mathrm{pH}$ front has already formed almost $10 \mathrm{~cm}$ from the anodic well at that time. In the EGM, the front takes more than one additional hour to form and does so at a more central position. In both cases, the front stops moving towards the cathode at similar speeds, although it reaches closer to the cathode positions in the SGM. This buffering capacity was experimentally observed in soils with a significant carbonate mineral content $[58$, 59]. During the electrokinetic treatment of a heavy metal contaminated soil, the dissolution of those minerals in the proximity of the anode produced the neutralization of the acid front. The $\mathrm{pH}$ values remained closed to neutrality and, consequently, the speciation of the heavy metals was significantly altered. In the present work, the different $\mathrm{pH}$ profiles also have an immediate effect on speciation and alter the distributions of secondary species of interest. Supplementary Figures SM 2 to SM 4 compare the normalised concentrations of several secondary species of $\mathrm{Na}^{+}$in the EGM and SGM. 


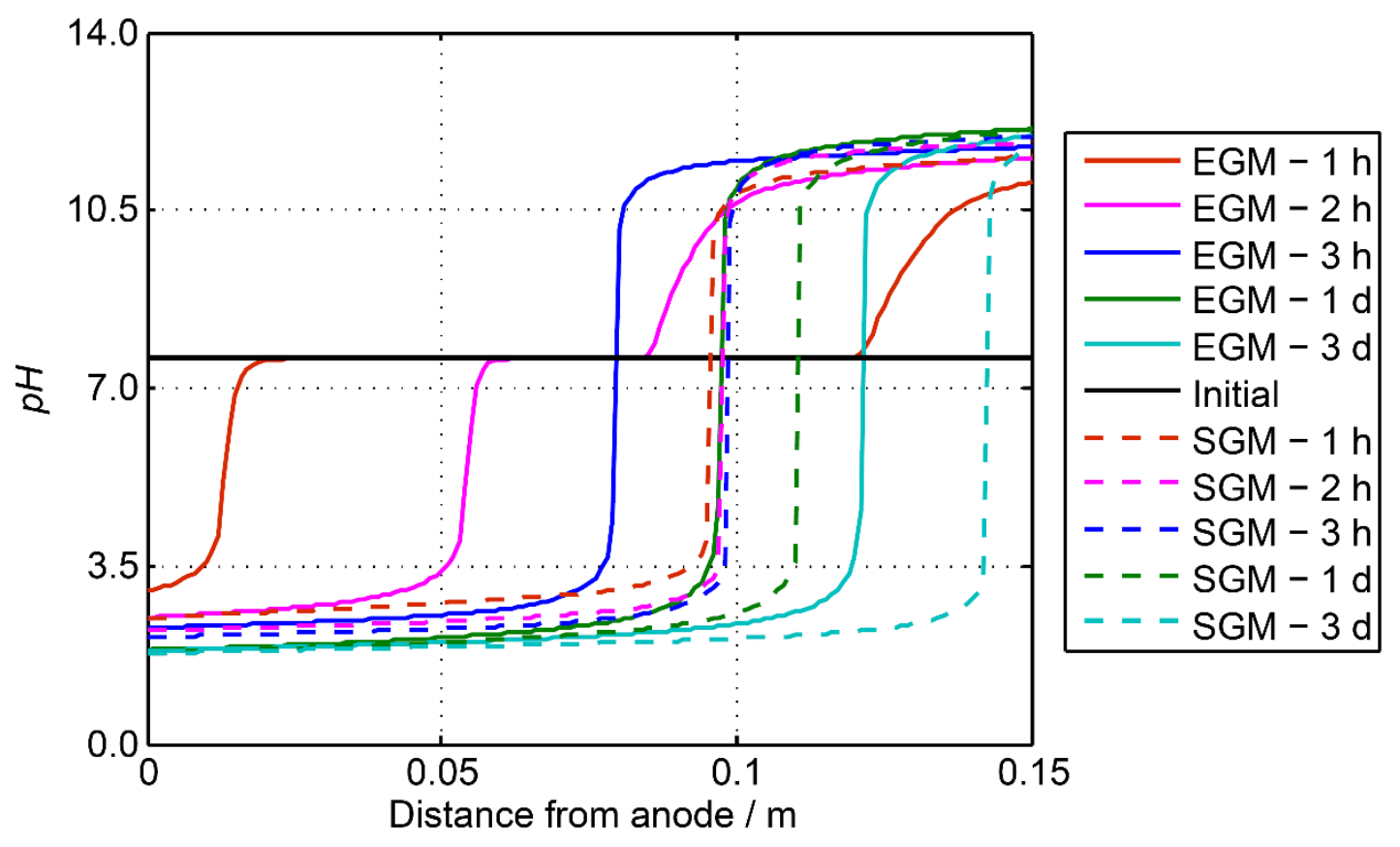

Figure 8. $p H$ profiles in the EGM an in the SGM at selected times.

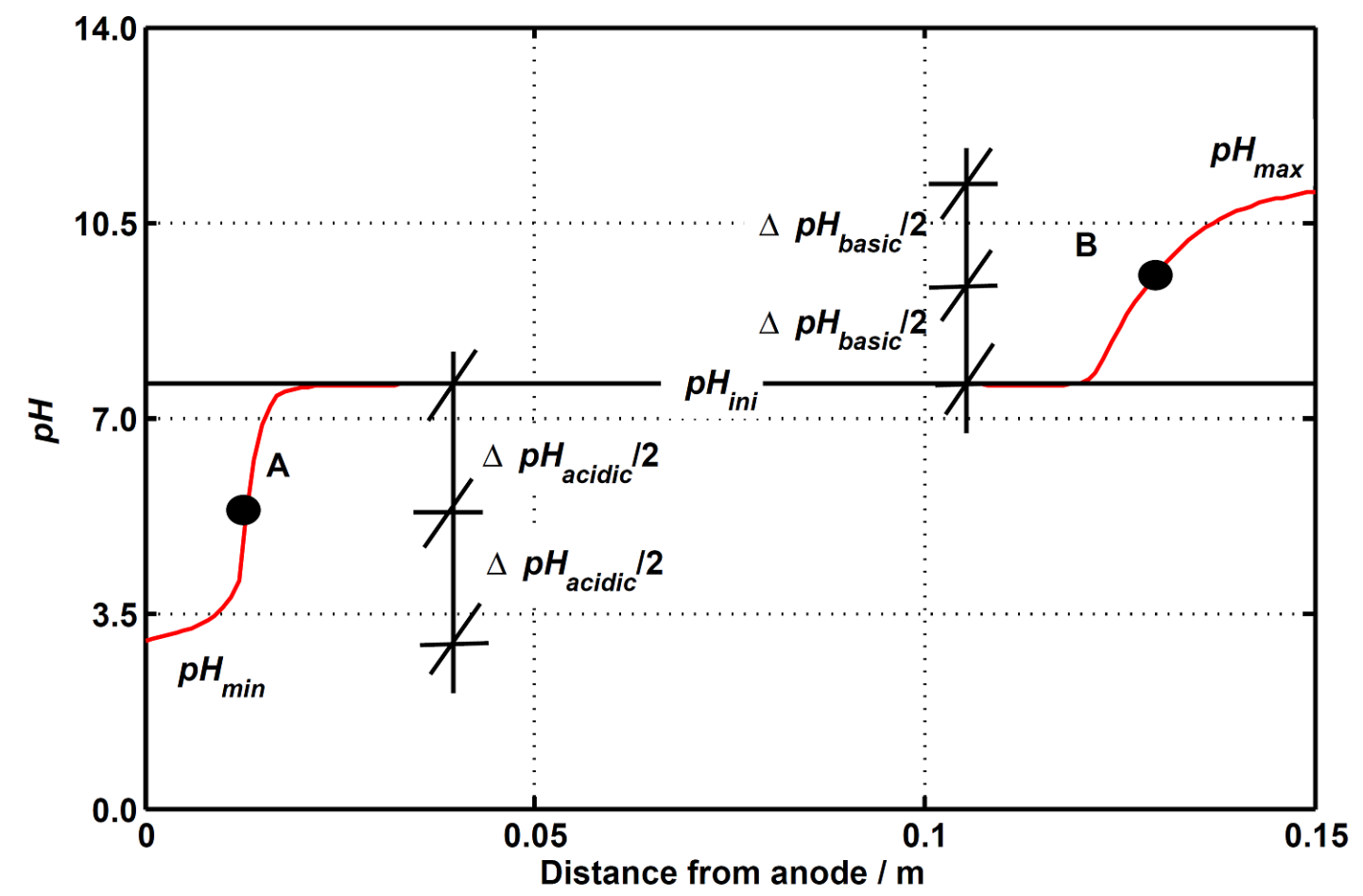

Generic time - Initial

Figure 9. Proposed mean location of the acidic (point A) and basic (point B) fronts. 


\section{CONCLUSIONS}

This paper proposed a conceptual model for the behaviour of an electrokinetic soil remediation system. Mass balance, chemical equilibrium, and constitutive equations were proposed. The formulation was applied to simulate the behaviour of a one-dimensional system that reproduces the configuration of a simple reactor. Two geochemical systems were considered. The first, the EGM, takes into account a realistic composition of natural porewater. The SGM, which has the same $\mathrm{pH}$ and concentration of mobile charges, assumes an idealised porewater composition with only four components $\left(\mathrm{Na}^{+}, \mathrm{Cl}^{-}, \mathrm{H}_{2} \mathrm{O}\right.$ and $\mathrm{H}^{+}$). The behavioural trends obtained with these models are consistent with those described by previous studies, including a long-term desaturation of the domain, a larger decrease in the electrical potential near the cathode, and greater electro-osmotic flow towards the cathode well. However, there are significant discrepancies between the EGM and the SGM with respect to the $\mathrm{pH}$, which can be considered the primary control variable in the soil remediation process. A different early temporal evolution of the $\mathrm{pH}$ is observed, which is much faster in the SGM. This causes much faster shifts in the basic and acidic fronts, and the final equilibrium is shifted towards the cathode well. This behaviour is caused by the buffering capacity of the system of carbonates in natural waters, which has not been considered in other models (such as the SGM). Buffering due to carbonates significantly affects the evolution, $\mathrm{pH}$ distribution, and ultimately the process efficiency of electrokinetic remediation because it affects the speciation of contaminants, the adsorption or desorption of soil particles, and their mobility or that of the liquid phase that contains them. Therefore, if numerical models are used to design actual remediation systems, previous simulations that use simplified geochemical systems may produce results that are significantly different from those obtained in reality. The delay in the formation and movement of $\mathrm{pH}$ fronts can cause greater energy consumption and duration 
of the remediation process than those expected by simple geochemical modelling. Therefore, it is important to include a complete geochemical model in electrokinetic remediation models to properly understand all of the processes that occur in natural soils and porewaters and to thus evaluate the efficiency of remediation technologies.

\section{SUPPLEMENTARY MATERIAL}

We included a notation list and some additional figures on the evolution of the total concentrations of the components and other variables in the electrolyte wells obtained with the EGM and the spatial distributions of different species of the $\mathrm{Na}^{+}$component obtained with the EGM and the SGM in the Supplementary Material.

\section{ACKNOWLEDGEMENTS}

This work was supported by the European Union [project FEDER OP2014-2020 of Castilla-La Mancha]; and by the Spanish Government [project CTM2013-45612-R].

\section{REFERENCES}

[1] Y.B. Acar, Principles of electrokinetic remediation, Environ. Sci. Technol., 27 (1993) 2638-2647.

[2] A.T. Yeung, S. Datla, Fundamental formulation of electrokinetic extraction of contaminants from soil, Can. Geotech. J., 32 (1995) 569-583.

[3] F.L. Souza, C. Saéz, J. Llanos, M.R.V. Lanza, P. Cañizares, M.A. Rodrigo, Solarpowered electrokinetic remediation for the treatment of soil polluted with the herbicide 2,4-D, Electrochim. Acta, 190 (2016) 371-377. 
[4] S. Yuan, Z. Zheng, J. Chen, X. Lu, Use of solar cell in electrokinetic remediation of cadmium-contaminated soil, J. Hazard. Mater., 162 (2009) 1583-1587.

[5] M. Zhou, S. Zhu, Y. Liu, X. Wang, Removal of fluorine from contaminated soil by electrokinetic treatment driven by solar energy, Environ. Sci. Pollut. Res., 20 (2013) $5806-5812$.

[6] P.C. Renaud, R.F. Probstein, Electroosmotic control of hazardous wastes, Physicochem. Hydrodyn., 6th Int Conf, Dedicated to the Memory of Veniamin Levich, 9 (1987) 345-360.

[7] A.P. Shapiro, P.C. Renaud, R.F. Probstein, Preliminary studies on the removal of chemical species from saturated porous media by electroosmosis, $\mathrm{PCH}$, PhysicoChem. Hydrodyn., 11 (1989) 785-802.

[8] A.P. Shaplro, R.F. Probstein, Removal of contaminants from saturated clay by electroosmosis, Environ. Sci. Technol., 27 (1993) 283-291.

[9] J.M. Paz-Garcia, K. Baek, I.D. Alshawabkeh, A.N. Alshawabkeh, A generalized model for transport of contaminants in soil by electric fields, J. Environ. Sci. Health, Part A: Toxic/Hazard. Subst. Environ. Eng., 47 (2012) 308-318.

[10] S.K. Puppala, A.N. Alshawabkeh, Y.B. Acar, R.J. Gale, M. Bricka, Enhanced electrokinetic remediation of high sorption capacity soil, J. Hazard. Mater., 55 (1997) 203-220.

[11] K.R. Reddy, U.S. Parupudi, S.N. Devulapalli, C.Y. Xu, Effects of soil composition on the removal of chromium by electrokinetics, J. Hazard. Mater., 55 (1997) 135-158. [12] R.A. Jacobs, M.Z. Sengun, R.E. Hicks, R.E. Probstein, Model and Experiments on Soil Remediation by Electric Fields, J. Environ. Sci. Health, Part A: Environ. Sci. Eng., 29 (1994) 1933-1955. 
[13] R.A. Jacobs, R.F. Probstein, Two-Dimensional Modeling of Electroremediation, AIChE J., 42 (1996) 1685-1696.

[14] A.N. Alshawabkeh, Y.B. Acar, Electrokinetic remediation. II: Theoretical model, J. Geotech. Eng., 122 (1996) 186-196.

[15] A.N. Alshawabkeh, Y.B. Acar, Removal of contaminants from soils by electrokinetics: A theoretical treatise, J. Environ. Sci. Health, Part A: Environ. Sci. Eng., 27 (1992) 1835-1861.

[16] Y.B. Acar, A.N. Alshawabkeh, R.J. Gale, Fundamental aspects of electrokinetic remediation of soils, Waste Manage., 13 (1993).

[17] M. Mascia, S. Palmas, A.M. Polcaro, A. Vacca, A. Muntoni, Experimental study and mathematical model on remediation of $\mathrm{Cd}$ spiked kaolinite by electrokinetics, Electrochim. Acta, 52 (2007) 3360-3365.

[18] C. Vereda-Alonso, J.M. Rodríguez-Maroto, R.A. García-Delgado, C. Gómez-Lahoz, F. García-Herruzo, Two-dimensional model for soil electrokinetic remediation of heavy metals: Application to a copper spiked kaolin, Chemosphere, 54 (2004) 895-903.

[19] C. Vereda-Alonso, C. Heras-Lois, C. Gomez-Lahoz, F. Garcia-Herruzo, J.M. Rodriguez-Maroto, Ammonia enhanced two-dimensional electrokinetic remediation of copper spiked kaolin, Electrochim. Acta, 52 (2007) 3366-3371.

[20] A.B. Ribeiro, J.M. Rodriguez-Maroto, E.P. Mateus, H. Gomes, Removal of organic contaminants from soils by an electrokinetic process: the case of atrazine. Experimental and modeling, Chemosphere, 59 (2005) 1229-1239.

[21] E.D. Mattson, R.S. Bowman, E.R. Lindgren, Electrokinetic ion transport through unsaturated soil: 1. Theory, model development, and testing, J. Contam. Hydrol., 54 (2002) 99-120. 
[22] E.D. Mattson, R.S. Bowman, E.R. Lindgren, Electrokinetic ion transport through unsaturated soil: 2. Application to a heterogeneous field site, J. Contam. Hydrol., 54 (2002) 121-140.

[23] A.Z. Al-Hamdan, K.R. Reddy, Electrokinetic remediation modeling incorporating geochemical effects, J. Geotech. Geoenviron. Eng., 134 (2008) 91-105.

[24] M.T. van Genuchten, Closed-form equation for predicting the hydraulic conductivity of unsaturated soils, Soil Sci. Soc. Am. J., 44 (1980) 892-898.

[25] J.K. Mitchell, K. Soga, Fundamentals of soil behavior, John Wiley \& Sons, Inc, Hoboken, New Jersey, USA, 2005.

[26] R.H. Brooks, A.T. Corey, Hydraulic Properties of Porous Media, Colorado State University1964.

[27] C.M. Bethke, Geochemical and Biogeochemical Reaction Modeling, Cambridge University Press, New York, USA, 2008.

[28] H. Chou, L. Wu, L. Zeng, A. Chang, Evaluation of solute diffusion tortuosity factor models for variously saturated soils, Water Resour. Res., 48 (2012) W10539.

[29] J. Bear, Dynamics of Fluids in Porous Media, Dover, 1972.

[30] J.O.M. Bockris, A.K.N. Reddy, Modern Electrochemistry. Volume 1. An Introduction to an Interdisciplinary Area, Springer, New York, N.Y, USA, 1970.

[31] J.D. Rhoades, N.A. Manteghi, P.J. Shouse, W.J. Alves, Soil Electrical Conductivity and Soil Salinity: New Formulations and Calibrations, Soil Sci. Soc. Am. J., 53 (1989) 433-439.

[32] S.P. Friedman, Soil properties influencing apparent electrical conductivity: A review, Comput. Electron. Agric., 46 (2005) 45-70.

[33] C.A.J. Appelo, Specific conductance: how to calculate, to use, and the pitfalls. , (2010). 
[34] D.L. Parkhurst, User's guide to PHREEQC - A computer program for speciation, reaction-path, advective-transport, and inverse geochemical calculations, User's Guide to PHREEQC (Version 2) - A Computer Program for Speciation, Batch-Reaction, OneDimensional Transport, and Inverse Geochemical Calculations, (1995).

[35] R.M. Garrels, C.L. Christ, Solutions, minerals, and equilibria, Harper \& Row, 1965. [36] COMSOL AB, COMSOL Multiphysics Reference Manual Version: COMSOL 5.1, 2015.

[37] Ö. Babur, V. Smilauer, T. Verhoeff, M. Van Den Brand, A survey of open source multiphysics frameworks in engineering in: J. Dongarra, S. Koziel, L. Leifsson, M. Lees, V.V. Krzhizhanovskaya, P.M.A. Sloot (Eds.) International Conference on Computational Science, ICCS 2015, Elsevier, Reykjavík, Iceland, 2015, pp. 1088-1097.

[38] D.L. Brown, J. Bell, D. Estep, W. Gropp, B. Hendrickson, S. Keller-McNulty, D. Keyes, J.T. Oden, L. Petzold, M. Wright, Applied Mathematics at the U.S. Department of Energy: Past, Present and a View to the Future, Lawrence Livermore National Laboratory (LLNL), Livermore, CA, USA, 2008, pp. 29.

[39] D.E. Keyes, L.C. McInnes, C. Woodward, W. Gropp, E. Myra, M. Pernice, J. Bell, J. Brown, A. Clo, J. Connors, E. Constantinescu, D. Estep, K. Evans, C. Farhat, A. Hakim, G. Hammond, G. Hansen, J. Hill, T. Isaac, X. Jiao, K. Jordan, D. Kaushik, E. Kaxiras, A. Koniges, K. Lee, A. Lott, Q. Lu, J. Magerlein, R. Maxwell, M. McCourt, M. Mehl, R. Pawlowski, A.P. Randles, D. Reynolds, B. Rivière, U. Rüde, T. Scheibe, J. Shadid, B. Sheehan, M. Shephard, A. Siegel, B. Smith, X. Tang, C. Wilson, B. Wohlmuth, Multiphysics simulations: Challenges and opportunities, Int. J. High Perform. Comput. Appl., 27 (2013) 4-83.

[40] F. Palacios, J. Alonso, K. Duraisamy, M. Colonno, J. Hicken, A. Aranake, A. Campos, S. Copeland, T. Economon, A. Lonkar, T. Lukaczyk, T. Taylor, Stanford 
University Unstructured (SU2): An open-source integrated computational environment for multi-physics simulation and design, 51st AIAA Aerospace Sciences Meeting including the New Horizons Forum and Aerospace Exposition, American Institute of Aeronautics and Astronautics2013.

[41] M.K. Gobbert, A. Churchill, G. Wang, T.I. Seidman, COMSOL Multiphysics for efficient solution of a transient reaction-diffusion system with fast reaction, in: Y. Rao (Ed.) COMSOL Conference 2009Boston, USA, 2009.

[42] V. Navarro, L. Asensio, T. Yustres, X. Pintado, J. Alonso, An elastoplastic model of bentonite free swelling, Eng. Geol. (Amsterdam, Neth.), 181 (2014) 190-201.

[43] V. Navarro, L. Asensio, A. Yustres, G. De la Morena, X. Pintado, Swelling and mechanical erosion of MX-80 bentonite: Pinhole test simulation, Eng. Geol. (Amsterdam, Neth.), 202 (2016) 99-113.

[44] R. López-Vizcaíno, V. Navarro, M.J. León, C. Risco, M.A. Rodrigo, C. Sáez, P. Cañizares, Scale-up on electrokinetic remediation: Engineering and technological parameters, J. Hazard. Mater., 315 (2016) 135-143.

[45] E.C. Leong, S. Tripathy, H. Rahardjo, Total suction measurement of unsaturated soils with a device using the chilled-mirror dew-point technique, Geotechnique, 53 (2003) 173-182.

[46] E. Giffaut, M. Grivé, P. Blanc, P. Vieillard, E. Colàs, H. Gailhanou, S. Gaboreau, N. Marty, B. Madé, L. Duro, Andra thermodynamic database for performance assessment: ThermoChimie, $\quad$ Appl. Geochem., 49 (2014) 225-236.

[47] M.J. Pikal, Ion-pair formation and the theory of mutual diffusion in a binary electrolyte, J. Phys. Chem., 75 (1971) 663-675. 
[48] C.A. Confederación Hidrográfica del Guadiana, Programa de seguimiento de las aguas subterráneas. Control de Vigilancia, Ministerio de Agricultura, Alimentación y Medio Ambiente, 2015.

[49] G. Skibsted, L.M. Ottosen, P.E. Jensen, J.M. Paz-Garcia, Electrochemical desalination of bricks - Experimental and modeling, Electrochim. Acta, 181 (2015) 2430.

[50] J.M. Paz-García, B. Johannesson, L.M. Ottosen, A.N. Alshawabkeh, A.B. Ribeiro, J.M. Rodríguez-Maroto, Modeling of electrokinetic desalination of bricks, Electrochim. Acta, 86 (2012) 213-222.

[51] J.M. Paz-García, B. Johannesson, L.M. Ottosen, A.B. Ribeiro, J.M. RodríguezMaroto, Simulation-based analysis of the differences in the removal rate of chlorides, nitrates and sulfates by electrokinetic desalination treatments, Electrochim. Acta, 89 (2013) 436-444.

[52] W. Stumm, J.J. Morgan, Aquatic Chemistry, 3rd ed., John Wiley \& Sons, New York, 1996.

[53] L. Gabrieli, A.N. Alshawabkeh, Influence of boundary conditions on transient excess pore pressure during electrokinetic applications in soils, J. Appl. Electrochem., 40 (2010) $1113-1121$.

[54] A.N. Alshawabkeh, T.C. Sheahan, X. Wu, Coupling of electrochemical and mechanical processes in soils under DC fields, Mech. Mater., 36 (2004) 453-465.

[55] S. Wieczorek, H. Weigand, M. Schmid, C. Marb, Electrokinetic remediation of an electroplating site: design and scale-up for an in-situ application in the unsaturated zone, Eng. Geol. (Amsterdam, Neth.), 77 (2005) 203-215.

[56] J. Yuan, M.A. Hicks, Influence of gas generation in electro-osmosis consolidation, Int. J. Numer. Anal. Methods Geomech., (2016). 
[57] R.E. Saichek, K.R. Reddy, Effect of $\mathrm{pH}$ control at the anode for the electrokinetic removal of phenanthrene from kaolin soil, Chemosphere, 51 (2003) 273-287.

[58] A.Z. Al-Hamdan, K.R. Reddy, Transient behavior of heavy metals in soils during electrokinetic remediation, Chemosphere, 71 (2008) 860-871.

[59] A.Z. Al-Hamdan, K.R. Reddy, Geochemical assessment of metal transport in glacial till during electrokinetic remediation, Environ. Monit. Assess. 139 (2008) 137-149. 


\section{Supplementary materials}

\section{Notation list}

\begin{tabular}{|c|c|c|}
\hline Parameters & Description & Units \\
\hline$a_{\mathrm{i}}$ & activity of species $i$ & $\mathrm{~mol} \mathrm{~kg}_{\mathrm{w}}{ }^{-1}$ \\
\hline$C_{\mathrm{m}}$ & total molal concentration of component $m$ & $\operatorname{mol~kg}{ }_{w}^{-1}$ \\
\hline$C_{\mathrm{m}}{ }^{\mathrm{o}}$ & initial molal concentration of component $m$ & $\mathrm{~mol} \mathrm{~kg}_{\mathrm{w}}{ }^{-1}$ \\
\hline$C_{\mathrm{m}}^{\mathrm{A}}$ & total molal concentration of component $m$ in the anodic well & $\mathrm{mol} \mathrm{kg}_{\mathrm{w}}{ }^{-1}$ \\
\hline$C_{\mathrm{m}}{ }^{\mathrm{C}}$ & total molal concentration of component $m$ in the cathodic well & $\mathrm{mol} \mathrm{kg}_{\mathrm{w}}{ }^{-1}$ \\
\hline$c_{\mathrm{i}}$ & molal concentration of species $i$ & $\operatorname{mol~kg}{ }_{\mathrm{w}}^{-1}$ \\
\hline$D_{\mathrm{i}}^{\mathrm{e}}$ & effective diffusion coefficient of species $i$ & $\mathrm{~m}^{2} \mathrm{~s}^{-1}$ \\
\hline$D_{\mathrm{i}}^{\mathrm{o}}$ & diffusion coefficient in water of species $i$ & $\mathrm{~m}^{2} \mathrm{~s}^{-1}$ \\
\hline$D_{\mathrm{i}}$ & diffusion/dispersion coefficient of species $i$ & $\mathrm{~m}^{2} \mathrm{~s}^{-1}$ \\
\hline$E$ & electric potential & $\mathrm{V}$ \\
\hline$F$ & Faraday constant & $\mathrm{C} \mathrm{mol}{ }^{-1}$ \\
\hline$g$ & gravity constant & $\mathrm{m} \mathrm{s}^{-1}$ \\
\hline$I$ & ionic strength & $\operatorname{mol~kg}{ }_{\mathrm{w}}^{-1}$ \\
\hline $\mathbf{i}$ & total current density & $\mathrm{A} \mathrm{m}^{-2}$ \\
\hline$i$ & species index & -- \\
\hline$K_{\text {sat }}{ }^{\mathrm{h}}$ & saturated hydraulic permeability & $\mathrm{m} \mathrm{s}^{-1}$ \\
\hline$K_{\mathrm{e}}^{\mathrm{h}}$ & effective hydraulic permeability & $\mathrm{m} \mathrm{s}^{-1}$ \\
\hline$K_{\mathrm{e}}^{\mathrm{eo}}$ & effective electroosmotic permeability & $\mathrm{m}^{2} \mathrm{~V}^{-1} \mathrm{~s}^{-1}$ \\
\hline $\mathbf{l}_{\mathrm{w}}$ & total mass flux of water & $\mathrm{kg} \mathrm{m}^{-2} \mathrm{~s}^{-1}$ \\
\hline $\mathbf{l}_{\mathrm{w}}{ }^{\mathrm{h}}$ & mass flux of water, Darcian contribution & $\mathrm{kg} \mathrm{m}^{-2} \mathrm{~s}^{-1}$ \\
\hline $\mathbf{l}_{\mathrm{w}}{ }^{\mathrm{eo}}$ & mass flux of water, electroosmotic contribution & $\mathrm{kg} \mathrm{m}^{-2} \mathrm{~s}^{-1}$ \\
\hline $\mathbf{l}_{\mathrm{m}}$ & total molar flux of component $m$ & $\mathrm{~mol} \mathrm{~m}^{-2} \mathrm{~s}^{-1}$ \\
\hline $\mathbf{l}_{\mathrm{m}}^{\mathrm{h}}$ & molar flux of component $m$, Darcian contribution & $\mathrm{mol} \mathrm{m}^{-2} \mathrm{~s}^{-1}$ \\
\hline $\mathbf{l}_{\mathrm{m}}{ }^{\mathrm{eo}}$ & molar flux of component $m$, electroosmotic contribution & $\mathrm{mol} \mathrm{m}^{-2} \mathrm{~s}^{-1}$ \\
\hline $\mathbf{l}_{\mathrm{m}}^{\mathrm{em}}$ & molar flux of component $m$, electromigration contribution & $\mathrm{mol} \mathrm{m}^{-2} \mathrm{~s}^{-1}$ \\
\hline
\end{tabular}




\begin{tabular}{|c|c|c|}
\hline $\mathbf{l}_{\mathrm{m}}^{\mathrm{dif}}$ & molar flux of component $m$, Fickian contribution & $\mathrm{mol} \mathrm{m}^{-2} \mathrm{~s}^{-1}$ \\
\hline$M$ & total number of components & -- \\
\hline$M_{\mathrm{m}}{ }^{\mathrm{A}}$ & moles of component $m$ in anodic well & mol \\
\hline$\dot{M}_{\mathrm{m}}^{\text {in A }}$ & inlet molar flow of component $m$ in anodic well & $\mathrm{mol} \mathrm{s}^{-1}$ \\
\hline$\dot{M}_{\mathrm{m}}^{\text {outA }}$ & outlet molar flow of component $m$ in anodic well & $\mathrm{mol} \mathrm{s}^{-1}$ \\
\hline$M_{\mathrm{m}}^{\mathrm{C}}$ & moles of component $m$ in cathodic well & mol \\
\hline$\dot{M}_{\mathrm{m}}^{\text {in } \mathrm{C}}$ & inlet molar flow of component $m$ in cathodic well & $\mathrm{mol} \mathrm{s}^{-1}$ \\
\hline$\dot{M}_{\mathrm{m}}^{\text {outC }}$ & outlet molar flow of component $m$ in cathodic well & $\mathrm{mol} \mathrm{s}^{-1}$ \\
\hline$m$ & component index & -- \\
\hline$m_{\mathrm{w}}$ & water mass per unit of total volume of soil & $\mathrm{kg} \mathrm{m}^{-3}$ \\
\hline$m_{\mathrm{m}}$ & mass of component $m$ por unidad de volumen & $\mathrm{mol} \mathrm{m}{ }^{-3}$ \\
\hline$m_{\mathrm{VG}}$ & parameter of the Van Genuchten retention curve & -- \\
\hline $\mathrm{N}$ & total number of species & -- \\
\hline $\mathbf{n}$ & normal vector & \\
\hline$n_{\mathrm{VG}}$ & parameter of the Van Genuchten retention curve & -- \\
\hline$P_{\mathrm{G}}$ & gas pressure & $\mathrm{kPa}$ \\
\hline$P_{\mathrm{L}}$ & liquid pressure & $\mathrm{kPa}$ \\
\hline $\mathbf{q}_{\mathrm{w}}$ & total volumetric flux of water & $\mathrm{m}^{3} \mathrm{~m}^{-2} \mathrm{~s}^{-1}$ \\
\hline $\mathbf{q}_{\mathrm{w}}{ }^{\mathrm{h}}$ & Darcian volumetric flux of water & $\mathrm{m}^{3} \mathrm{~m}^{-2} \mathrm{~s}^{-1}$ \\
\hline $\mathbf{q}_{\mathrm{w}}{ }^{\mathrm{eo}}$ & electroosmotic volumetric flux of water & $\mathrm{m}^{3} \mathrm{~m}^{-2} \mathrm{~s}^{-1}$ \\
\hline $\mathbf{q}_{\mathrm{i}}^{\mathrm{em}}$ & migration velocity of species $i$ & $\mathrm{~m} \mathrm{~s}^{-1}$ \\
\hline$Q$ & total electric charge & $\mathrm{C} \mathrm{m} \mathrm{m}^{-3}$ \\
\hline$R$ & ideal gas constant & $? ?$ \\
\hline$R_{\mathrm{m}}$ & rate of production/consumption of component $m$ & mol m${ }^{-3} \mathrm{~s}^{-1}$ \\
\hline$R_{\mathrm{Q}}$ & rate of generation/consumption of electric charge & $\mathrm{C} \mathrm{m}^{-3} \mathrm{~s}^{-1}$ \\
\hline$R_{\mathrm{m}}{ }^{\mathrm{A}}$ & rate of production/consumption of component $m$ in anodic well & $\mathrm{mol} \mathrm{s}^{-1}$ \\
\hline$R_{\mathrm{m}}^{\mathrm{C}}$ & rate of production/consumption of component $m$ in cathodic well & $\mathrm{mol} \mathrm{s}^{-1}$ \\
\hline $\mathrm{Sr}$ & saturation degree & -- \\
\hline$S^{A}$ & anodic surface & $\mathrm{m}^{2}$ \\
\hline
\end{tabular}




\begin{tabular}{|c|c|c|}
\hline$S^{C}$ & cathodic surface & $\mathrm{m}^{2}$ \\
\hline$s$ & matric suction & $\mathrm{kPa}$ \\
\hline$T$ & temperature & $\mathrm{K}$ \\
\hline$V^{A}$ & anolyte volume & $\mathrm{m}^{3}$ \\
\hline$V^{C}$ & catholyte volume & $\mathrm{m}^{3}$ \\
\hline$z$ & vertical coordinate & $\mathrm{m}$ \\
\hline$z_{\mathrm{i}}$ & charge number of species $i$ & \\
\hline$\alpha_{\mathrm{VG}}$ & parameter of the Van Genuchten retention curve & $\mathrm{kPa}^{-1}$ \\
\hline$\alpha_{\mathrm{i}}^{\mathrm{m}}$ & molar contribution of component $m$ to the production of species $i$ & -- \\
\hline$\gamma_{\mathrm{i}}$ & activity coefficient of species $i$ & -- \\
\hline$\delta_{1}^{\mathrm{L}}$ & longitudinal dispersivity of species $i$ & $\mathrm{~m}$ \\
\hline$\lambda_{\mathrm{o}, \mathrm{i}}$ & ionic molal conductivity of species $i$ & $\mathrm{~S} \mathrm{~kg}_{\mathrm{w}} \mathrm{m}^{-1} \mathrm{~mol}^{-1}$ \\
\hline$\mu_{\mathrm{i}}^{\mathrm{e}}$ & effective ionic mobility of species $i$ & $\mathrm{~m}^{2} \mathrm{~V}^{-1} \mathrm{~s}^{-1}$ \\
\hline$\mu_{\mathrm{i}}^{\mathrm{o}}$ & ionic mobility of species $i$ at infinite dilution in water & $\mathrm{m}^{2} \mathrm{~V}^{-1} \mathrm{~s}^{-1}$ \\
\hline$\rho_{\mathrm{w}}$ & water density & $\mathrm{kg} \mathrm{m}^{-3}$ \\
\hline$\sigma_{\mathrm{a}}$ & aparent electrical conductivity & $\mathrm{S} \mathrm{m}^{-1}$ \\
\hline$\sigma_{\mathrm{s}}$ & electrical conductivity of solid phase & $\mathrm{S} \mathrm{m}^{-1}$ \\
\hline$\sigma_{\mathrm{a}}$ & electrical conductivity of aqueous phase & $\mathrm{S} \mathrm{m}^{-1}$ \\
\hline$\tau$ & tortuosity & -- \\
\hline$\phi$ & porosity & -- \\
\hline$\varphi_{\mathrm{m}}^{\mathrm{A}}$ & mol of $m$ produced per mol of changed electrons in anodic surface & - \\
\hline$\varphi_{\mathrm{m}}^{\mathrm{C}}$ & mol of $m$ produced per mol of changed electrons in cathodic surface & - \\
\hline$\partial / \partial t$ & time-derivative operator & $\mathrm{s}^{-1}$ \\
\hline$\nabla \cdot$ & divergence operator & $\mathrm{m}^{-1}$ \\
\hline$\nabla$ & gradient operator & $\mathrm{m}^{-1}$ \\
\hline
\end{tabular}



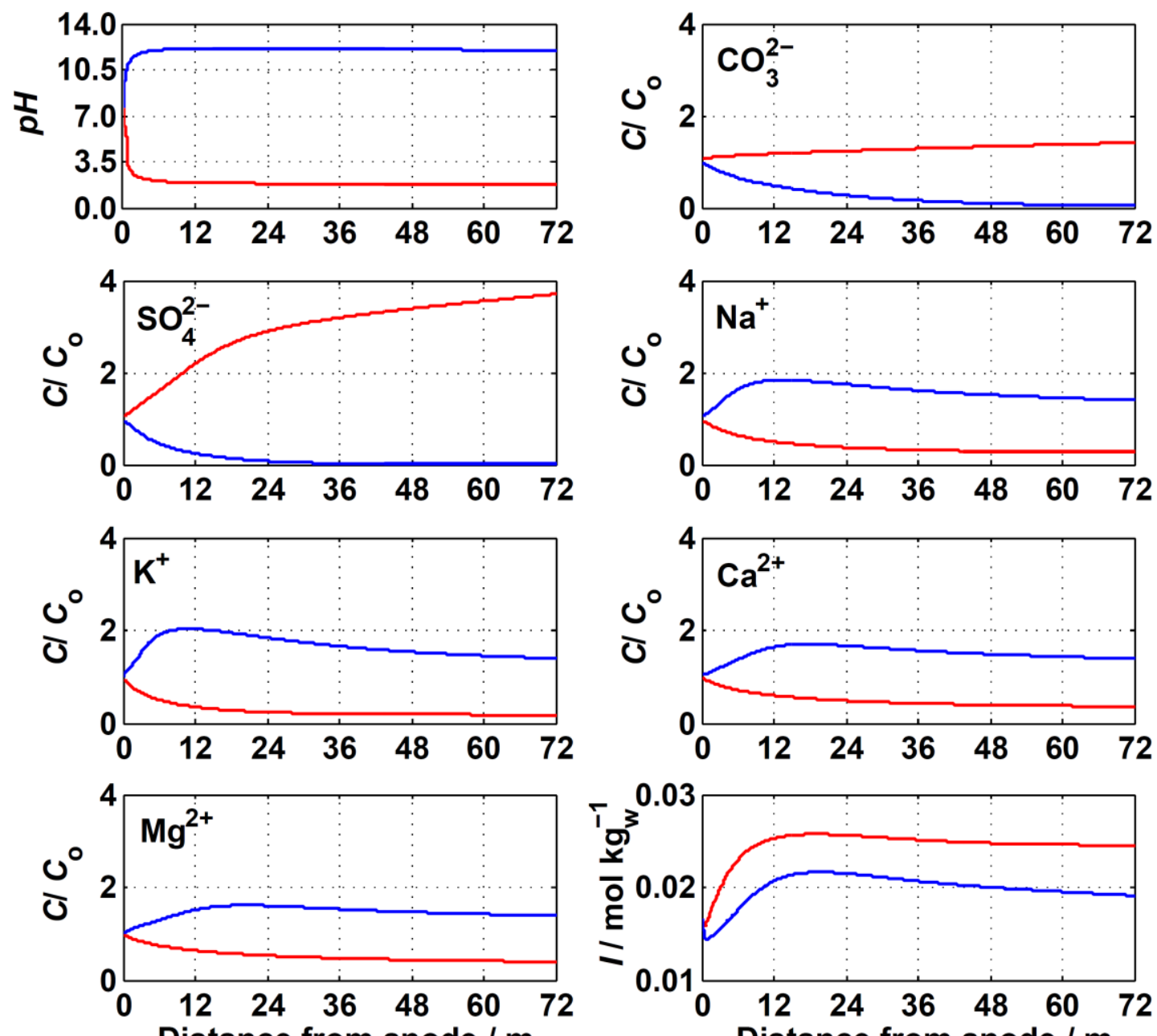

Distance from anode / $\mathrm{m}$

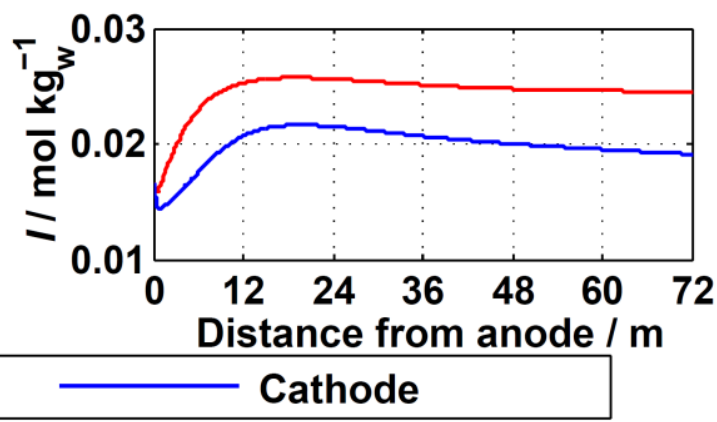

Figure SM 1. Evolution in the electrolyte wells for the EGM of (a) $p H$; (b) total normalised concentration of the $\mathrm{CO}_{3}^{2-}$ component; (c) total normalised concentration of the $\mathrm{SO}_{4}^{2-}$ component; (d) total normalised concentration of the $\mathrm{Na}^{+}$component; (e) total normalised concentration of the $\mathrm{K}^{+}$component; (f) total normalised concentration of the $\mathrm{Ca}^{2+}$ component; (g) total normalised concentration of the $\mathrm{Mg}^{2+}$ component; (h) Ionic strength, $I$. 


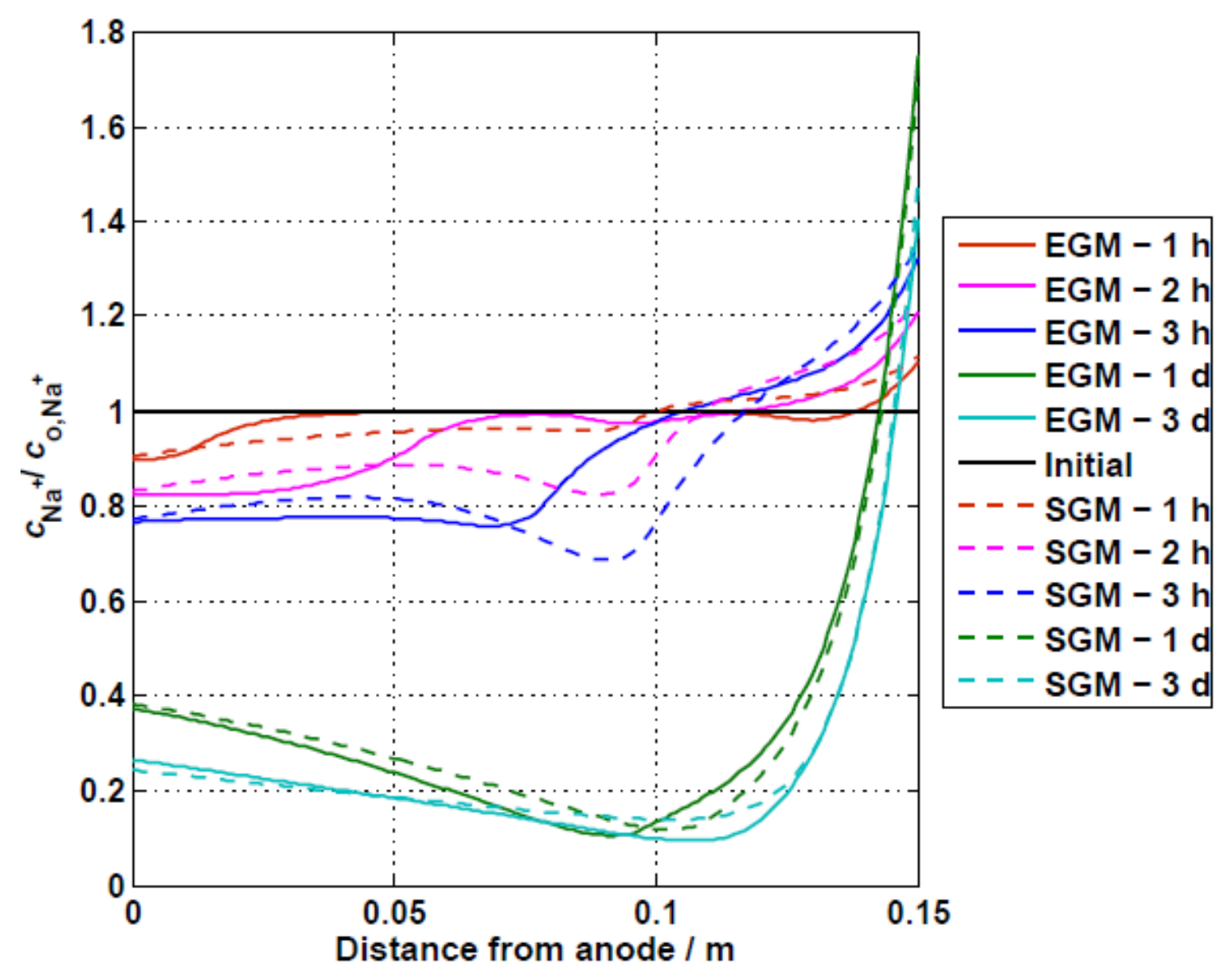

Figure SM 2. Spatial distribution of the normalised concentration of the species $\mathrm{Na}^{+}$in the EGM and the SGM at selected times. 


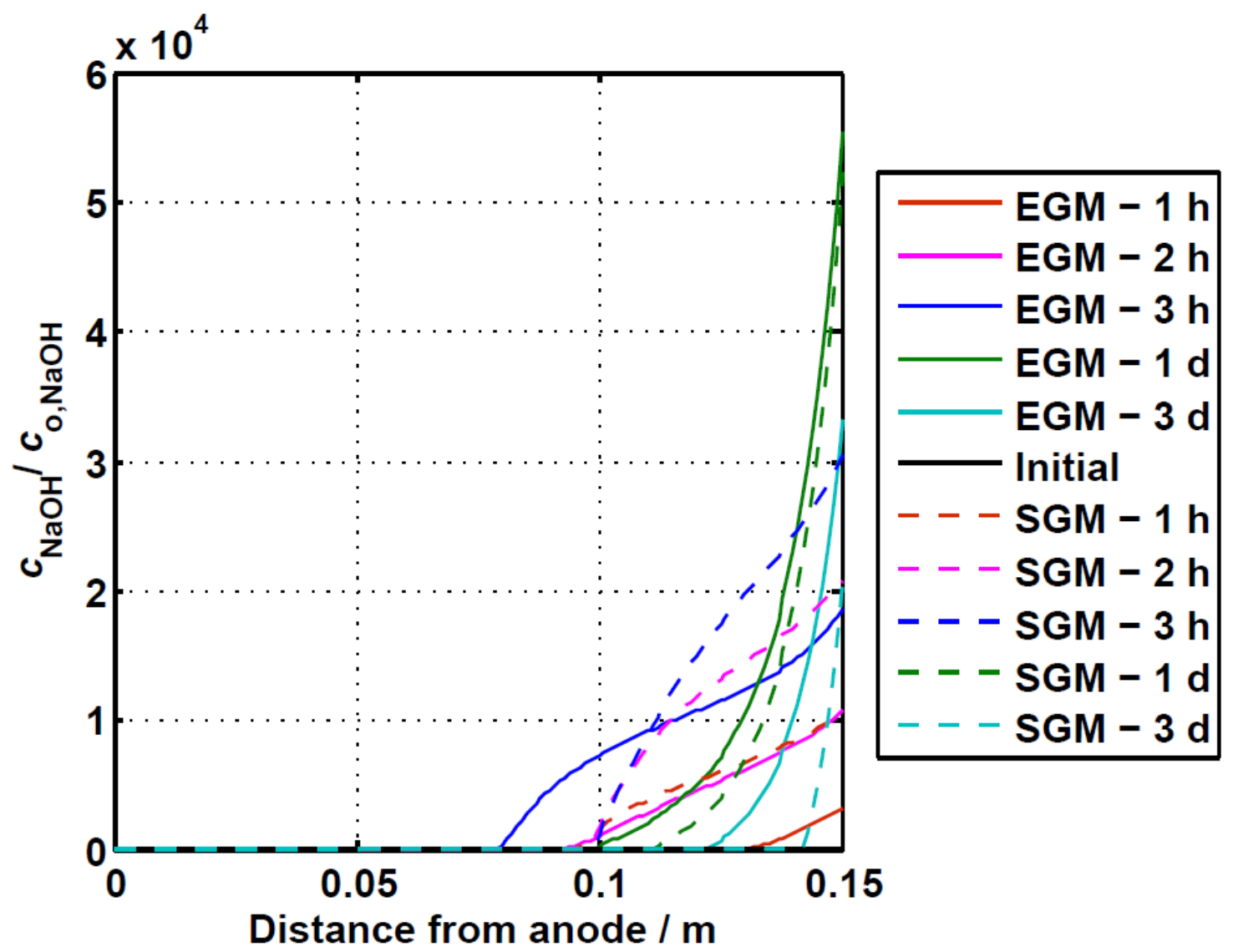

Figure SM 3. Spatial distribution of the normalised concentration of the species $\mathrm{NaOH}$ in the EGM and the SGM at selected times. 


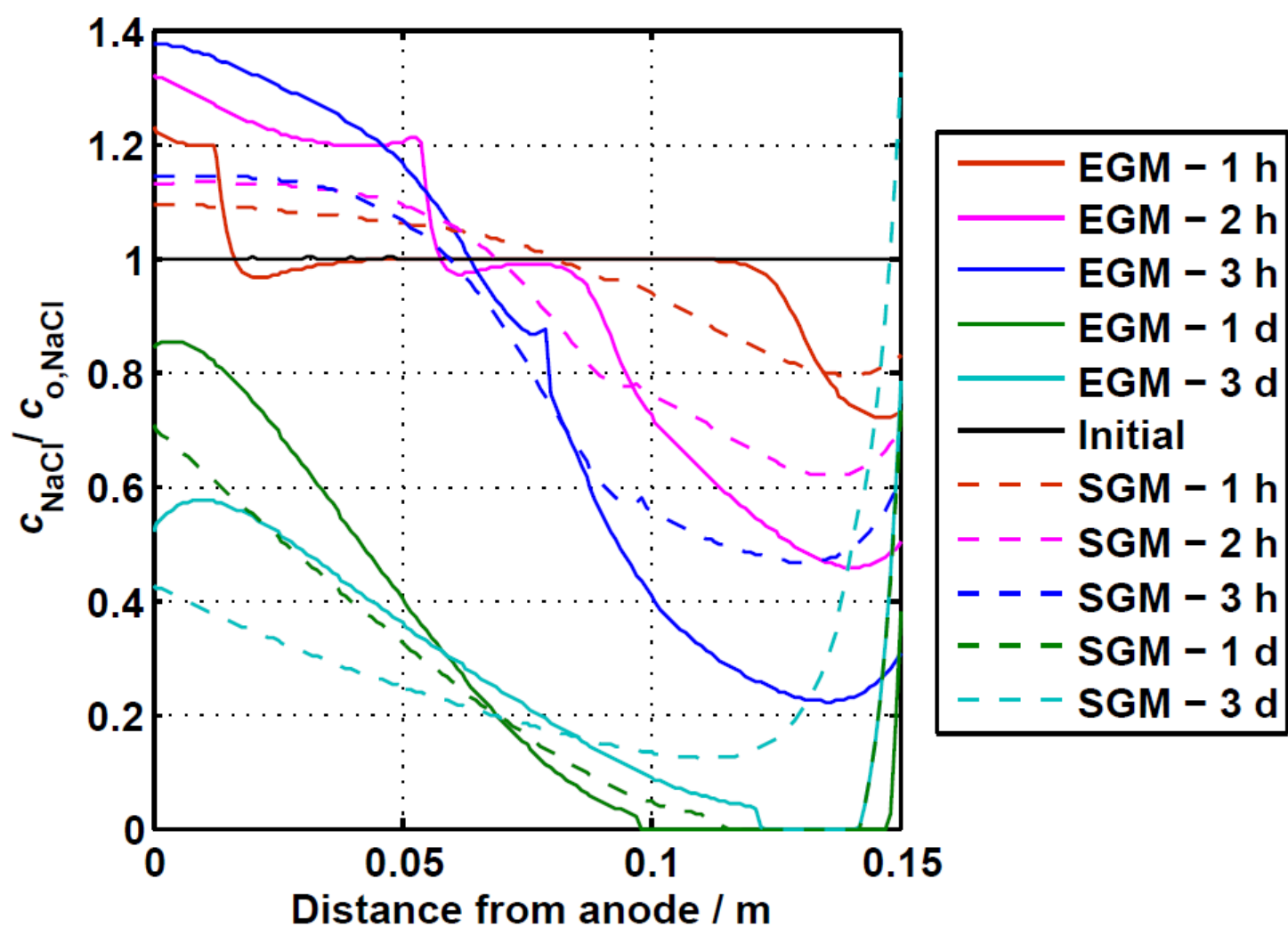

Figure SM 4. Spatial distribution of the normalised concentration of the species $\mathrm{NaCl}$ in the EGM and the SGM at selected times. 